Research article

urn:lsid:zoobank.org:pub:DC2105E2-F6C5-4B49-928F-BFD3A361CC52

\title{
The species of Ctenopelma Holmgren (Hymenoptera, Ichneumonidae) from China
}

\author{
Shu-Ping SUN ${ }^{1}$, Tao $\mathrm{LI}^{2}$, Mao-Ling SHENG ${ }^{3, *} \& \mathrm{Chun} \mathrm{GAO}^{4}$ \\ ${ }^{1,2,3}$ General Station of Forest and Grassland Pest Management, National Forestry and Grassland \\ Administration, 58 Huanghe North Street, Shenyang 110034, P.R. China. \\ ${ }^{4}$ Forest Pest Control and Quarantine Station of Kuandian Manzu Autonomous County, \\ Kuandian Liaoning 118200, P.R. China. \\ *Corresponding author: shengmaoling@163.com \\ ${ }^{1}$ urn:1sid:zoobank.org:author:974C0354-6118-4EA9-890F-EF5ECE8F257A \\ ${ }^{2}$ urn:lsid:zoobank.org:author:AE2C4D7F-6132-4A33-A5EC-04CF541BD80E \\ ${ }^{3}$ urn:lsid:zoobank.org:author:3C0EBDB7-26F7-469B-8DB1-5C7B1C6D9B89 \\ ${ }^{4}$ urn:lsid:zoobank.org:author:5A4F55CC-426B-4BB8-B71A-CFEDC82BF363
}

\begin{abstract}
Eleven species of Ctenopelma Holmgren, 1857 are reported from China. Five species are new to science: C. labiatum Sheng, Sun \& Li sp. nov., from Ningxia Hui Autonomous Region, C. lii Sheng, Sun \& Li sp. nov., from Liaoning province, C. rufofasciatum Sheng, Sun \& Li sp. nov., reared from Cephalcia lariciphila (Wachtl, 1898) from Beijing, C. pineatum Sheng, Sun \& Li sp. nov., reared from Acantholyda posticalis (Matsumura, 1912) and Cephalcia lariciphila from Beijing and Henan, Shanxi, Shan'xi, Liaoning, Jilin and Heilongiiang provinces, and C. spiraculare Sheng, Sun \& Li sp. nov., reared from Cephalcia lariciphila from Henan and Shanxi provinces. One species, C. nigrum Holmgren, 1857, reared from Cephalcia lariciphila in Beijing, is a new record for China. Ctenopelma tomentosum (Desvignes, 1856) was reared from Neurotoma sibirica Gussakovskij, 1935 (new host record) in Liaoning province. A key to species of Ctenopelma known in China is provided.
\end{abstract}

Keywords. Key, new species, Ctenopelma, Ctenopelmatinae, taxonomy.

Sun S.-P., Li T., Sheng M.-L. \& Gao C. 2019. The species of Ctenopelma Holmgren (Hymenoptera, Ichneumonidae) from China. European Journal of Taxonomy 545: 1-31. https://doi.org/10.5852/ejt.2019.545

\section{Introduction}

Ctenopelma Holmgren, 1857 (Hymenoptera, Ichneumonidae, Ctenopelmatinae) comprises 44 species (Yu et al. 2016), of which three are from the Oriental Region (Sheng \& Sun 2009), 17 are from the Eastern Palaearctic Region (ten of them also found in the Western Palaearctic) (Aubert 1985, 1987, 2000; Kasparyan 2004), 13 from the Western Palaearctic (Gravenhorst 1829; Heinrich 1949, 1953; Aubert 1985, 2000) and 24 are from the Nearctic Region (Barron 1981). Five species of Ctenopelma have been reported from China to date (Sheng \& Sun 2014; Yu et al. 2016). The Palaearctic species were revised with a key by Kasparyan (2004). The Nearctic species were reported with a key by Barron 
(1981). The Oriental species were reported by Kasparyan (2004) and Sheng \& Sun (2009). The status of the genus was elucidated by Barron (1981), Townes (1970) and by Kasparyan (2004).

The known hosts of Ctenopelma belong to the webspinning sawflies family Pamphiliidae (Barron 1981; Shaw et al. 2003; Kasparyan 2004). Records also exists from Megalodontes klugi Leach, 1817 (Megalodontesidae) (Pschorn-Walcher 1990) and Cimbex betuleti (?) (Rudow 1917) (= Trichiosoma lucorum (Linnaeus, 1758) (Cimbicidae), although the latter record must remain doubtful.

\section{Material and methods}

\section{Institutional abbreviations}

GSFGPM $=$ General Station of Forest and Grassland Pest Management, National Forestry and Grassland Administration, P.R. China

$\mathrm{KPMNH}=$ Kanagawa Prefectural Museum of Natural History, Odawara, Japan

NHMUK $=$ Natural History Museum, London, United Kingdom

ZISP $=$ Zoological Institute of the Russian Academy of Sciences, St. Petersburg, Russia

ZSMG = Zoologische Staatssammlung München, Germany

\section{Specimen collection and rearing}

Rearing parasitoids: The 'pupation chambers' with mature larvae of webspinning sawflies were collected under naturally heavily infested trees and reared in the laboratory at room temperature. The emerged insects were collected daily.

Direct collection: Parasitoid adults were collected using sweep nets mainly in the natural reserves of Heilongjiang, Hubei, Jilin, Jiangxi, Liaoning, Shanxi, Shannxi and Zhejiang provinces, and in Ningxia Hui Autonomous Region (China); collection by interception traps ( $\mathrm{Li}$ et al. 2012) was also used in the forests of Beijing, Henan, Jiangxi and Shandong.

Examined material. The specimens of Ctenopelma deposited in NHMUK and ZSMG, were examined. The photos of the types of Xaniopelma altitudinis Heinrich, 1953, Ctenopelma boreoalpina Heinrich, 1949, Ischnus karafutonis Matsumura, 1911 and Mesochorus lucifer Gravenhorst, 1829, taken by Watanabe (KPMNH), were checked and compared to the new species by the Corresponding author.

Images were taken using a Leica M205A stereo microscope with LAS Montage MultiFocus. Morphological terminology is mostly based on Gauld (1991).

All examined specimens including types and paratypes are deposited in the Insect Museum, GSFGPM.

\section{Results}

Class Hexapoda Blainville, 1816

Order Hymenoptera Linnaeus, 1758

Superfamily Ichneumonoidea Latreille, 1802

Family Ichneumonidae Latreille, 1802

Subfamily Ctenopelmatinae Förster, 1869

Tribe Ctenopelmatini Förster, 1869

Ctenopelma Holmgren, 1857

Ctenopelma Holmgren, 1857: 117. Type species: Ctenopelma nigrum Holmgren, 1857. 


\section{Diagnosis}

Clypeus slightly or strongly convex medially, its apical margin concave or almost truncate medially. Mandible large, lower tooth longer than or almost same length as upper tooth. Genal carina reaching to base of mandible. Median portion of antenna slightly thickened. Upper margin of pronotum paralleled with a more or less distinct groove. Claw pectinate. First tergite with large, deep glymma. Anterior lateral portion of second tergite from anterior margin to spiracle with longitudinal carina. Apical portion of female metasoma more or less compressed. Posterior margin of female tergite 8 distinctly projecting backward medially.

\section{Key to species of Ctenopelma Holmgren, 1857 known from China (females only)}

1. Ovipositor sheath comparatively long, at least $10 \times$ as long as its maximum width (C. brevicorne Kuzin, 1950 from Korea, Mongolia, Russian Far East and Transbaikalia has ovipositor sheath about

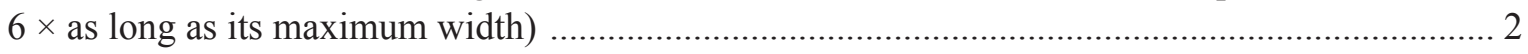

- Ovipositor sheath comparatively short, at most $4 \times$ as long as its maximum width ........................ 4

2. First tergite abruptly, strongly narrowed in front of spiracle, spiracle strongly convex. Postpetiole slightly to comparatively convex, shorter than its apical width. Second tergite shorter than its posterior width. Hind wing vein 1-cu distinctly shorter than cu-a (Figs 43-53)

C. spiraculare Sheng, Sun \& Li sp. nov.

- First tergite almost evenly convergent from posterior margin to base, spiracle not or slightly convex. Postpetiole normal, at most slightly convex, distinctly longer than its posterior width. Second tergite as long as or longer than its posterior width. Hind wing vein 1-cu longer, as long as, or slightly shorter than cu-a

3. Apical margin of clypeus distinctly concave. First tergite approximately $2.2 \times$ as long as apical width. At least tergites 2 and 3 of metasoma red-brown C. lucifer (Gravenhorst, 1829)

- Apical margin of clypeus truncate. First tergite 2.6 to $2.7 \times$ as long as apical width. Only tergite 2 red-brown. Hind tibia with wide median dull whitish marking (Figs 24-34)

C. rufofasciatum Sheng, Sun \& Li sp. nov.

4. Ovipositor without subapical dorsal notch, apical half of ovipositor needle-shaped; basal half of ovipositor strongly and abruptly thickened. Claw not pectinate or indistinctly pectinate. Head except apical portion of clypeus and mandible, mesosoma except tegula, metasoma and all coxae black ...

- Ovipositor with subapical dorsal notch. Claw distinctly pectinate. Head, mesosoma, metasoma, or coxae with more or less yellow or red-brown coloration

5. Postpetiole, tergites 2 and 3 almost entirely shiny, with distinct punctures. Hind leg entirely black (Figs 35-42)

C. pineatum Sheng, Sun \& Li sp. nov.

- Postpetiole, tergite 2 and basal half of tergite 3 scabrous, without punctures. Hind leg, at least femur, red-brown

C. nigrum Holmgren, 1857

6. Labium large, ligula long, conspicuously exposed below mandible. Areolet very small, with long stalk, $1.7 \times$ as long as height of areolet. Median longitudinal carinae of propodeum between base and posterior transverse carina parallel; area superomedia separated from area petiolaris by distinct carina; lateral longitudinal carinae present. Basal 0.6 of claw distinctly pectinate (Figs 1-11)

C. labiatum Sheng, Sun \& Li sp. nov.

- Labium small, ligula indistinct. Areolet comparatively large; without stalk, or of lesser height than areolet. Median longitudinal carinae of propodeum convergent anteriorly, or distinctly narrowed 
medially (Fig. 19); area superomedia often not separated from area petiolaris by carina; lateral longitudinal carina absent or present. Claw indistinctly or fully pectinate

7. Lateral longitudinal carina of propodeum between anterior margin and posterior transverse carina complete and strong. Face slightly shagreened, with dense punctures. Body mainly black; coxae and hind femora red-brown

C. ruficoxator Aubert, 1987

- Lateral longitudinal carina of propodeum between basal margin and posterior transverse carina absent, or apical portion indistinctly present. Face distinctly shagreened, with sparse fine punctures. Body with distinct yellowish white, brown and yellowish brown spots

8. Head mainly red-brown, with black spots. Mesosoma red-brown or yellow-brown, with irregular black spots. Metasoma red-brown or yellow-brown (Figs 57-59) C. rufescentis Sheng, 2009

- Head black, or only face yellow. Mesosoma black

9. Area superomedia and area petiolaris combined (not separated by carina). Lateral longitudinal carina of propodeum between anterior and posterior transverse carina absent. Face black

C. tomentosum (Desvignes, 1856)

- Area superomedia separated from area petiolaris by distinct carina. Lateral longitudinal carina of propodeum present partly, or absent. Face yellow

10. Ovipositor sheath approximately $0.7 \times$ as long as hind first tarsomere. Fore and middle coxae yellowbrown. Hind coxa mainly and hind femur entirely brown to red-brown (Figs 54-56)

C. melanothoracicum Sheng, 2009

- Ovipositor sheath almost as long as hind first tarsomere. All coxae and hind femur entirely black (Figs 12-23) C. lii Sheng, Sun \& Li sp. nov.

Ctenopelma labiatum Sheng, Sun \& Li sp. nov. urn:1sid:zoobank.org:act:AB886000-ED3E-4732-B3D9-501905724244

Figs 1-11

\section{Diagnosis}

Labium large, ligula long and conspicuously exposed below mandible. Areolet very small, with long stalk ( $1.7 \times$ as long as height of areolet). Median longitudinal carina of propodeum (between posterior transverse carina and anterior margin) parallel (Fig. 8). Ovipositor sheath (Fig. 11) wide, ovoid, about $2 \times$ as long as its width, without dorsoapical emargination. Metasoma almost entirely yellowish brown. Apical half of antenna yellow (Fig. 1).

\section{Etymology}

The specific name is derived from the large labium.

\section{Material examined}

Holotype

CHINA • P; Ningxia Hui Autonomous Region, Mt. Liupan; 9 Jul. 2005; interception trap; GSFGPM.

\section{Description}

Female

MEASUREMENTS. Body length approximately $10.3 \mathrm{~mm}$. Fore wing length approximately $7.6 \mathrm{~mm}$. Ovipositor sheath length approximately $0.5 \mathrm{~mm}$. 
HEAD. Inner orbits almost parallel, slightly impressed nearby antennal socket. Face (Fig. 2) approximately $1.5 \times$ as wide as long, with dense shallow punctures; upper margin with median small longitudinal tubercle. Clypeus approximately $2.8 \times$ as wide as long, smooth, with fine, sparse punctures; median portion of apical margin concave. Mandible with large shallow elongate punctures and buff setae; upper tooth approximately as long as lower tooth. Malar space coriaceous. Malar space approximately $0.2 \times$ as long as basal width of mandible. Gena (Fig. 3) with indistinct fine punctures and grey hairs, evenly convergent backwardly. Vertex (Fig. 4) with texture as that of gena. Postocellar line approximately $0.8 \times$ as long as ocular-ocellar line. Antenna with 34 flagellomeres; ratio of length from first to fifth flagellomeres approximately: 1.4:1.1:1.0:1.0:1.0. Occipital carina complete, genal carina reaching to base of mandible.

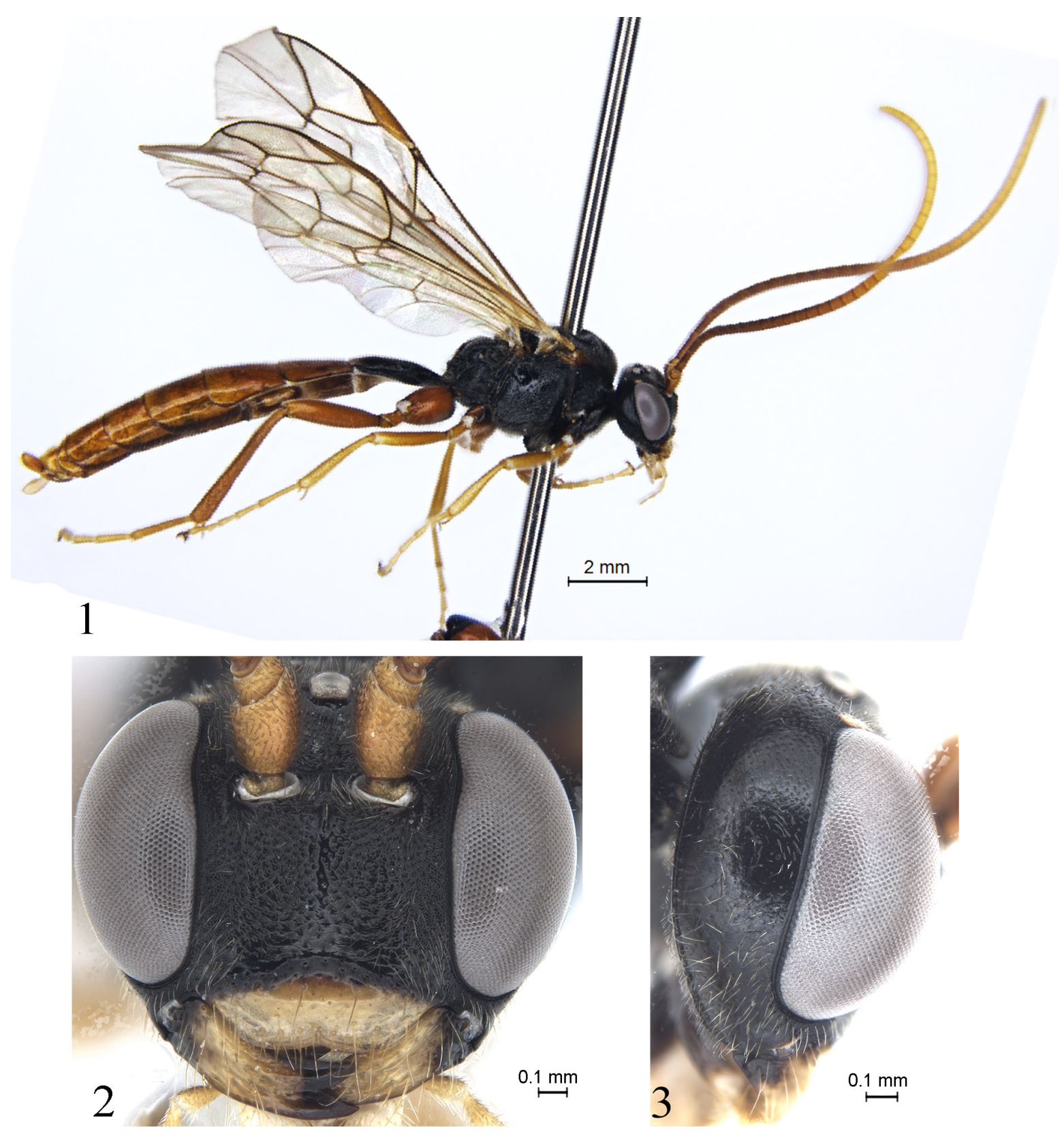

Figs 1-3. Ctenopelma labiatum Sheng, Sun \& Li sp. nov., holotype, o (GSFGPM). 1. Habitus, lateral view. 2. Head, anterior view. 3. Head, lateral view.. 
Mesosoma. Anterior margin of pronotum with dense fine punctures, lateral concavity shallow, wide, with irregular short wrinkles; upper-posterior portion almost shiny, with distinct, fine punctures. Mesoscutum (Fig. 5) smooth, shiny, with relative dense punctures, distance between punctures $0.2-2.5 \times$ diameter of puncture, denser on posteriormedian portion. Anterior portion of notaulus present. Scutoscutellar groove relatively shallow, smooth. Scutellum with fine punctures, posterior portion with relative long

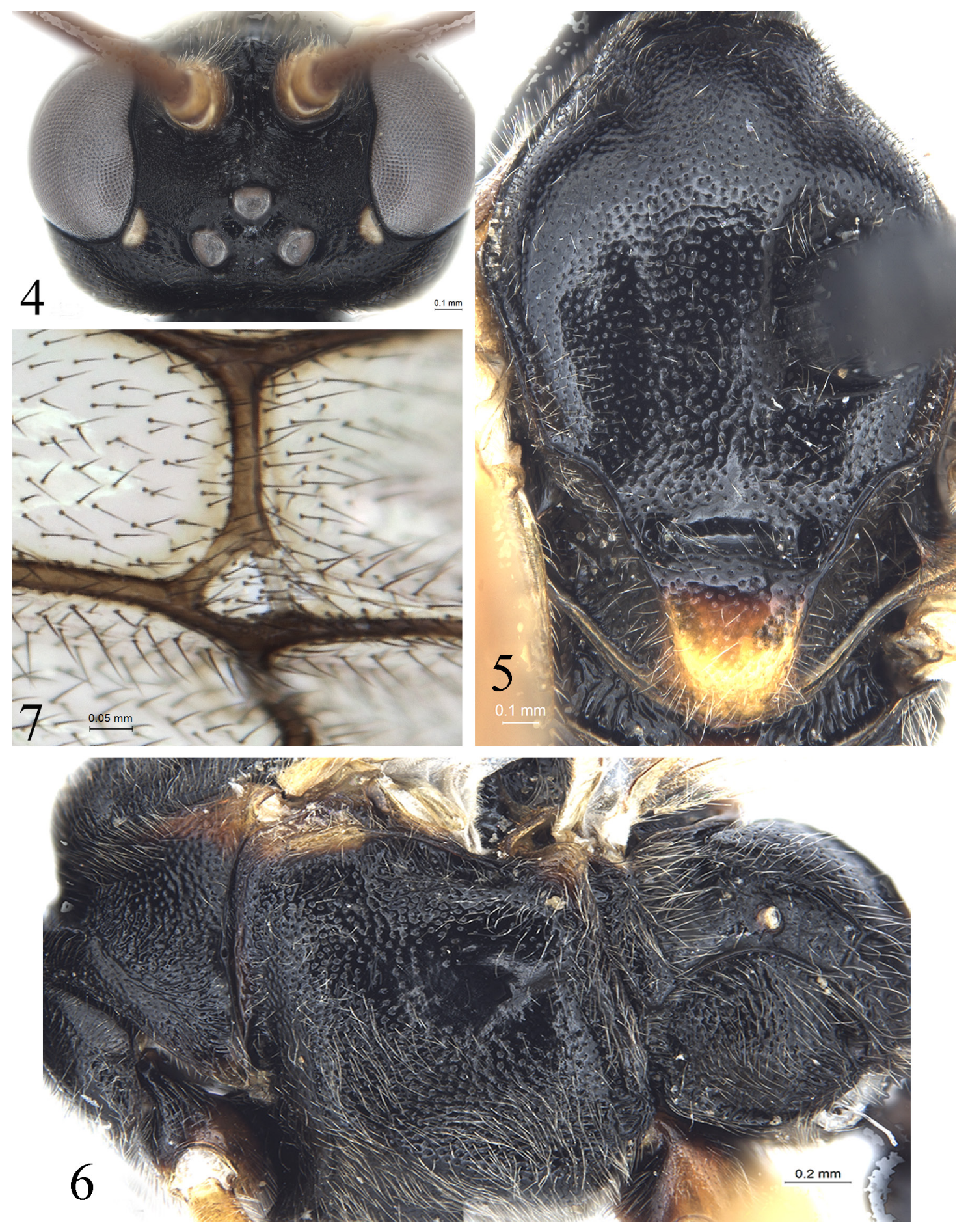

Figs 4-7. Ctenopelma labiatum Sheng, Sun \& Li sp. nov., holotype, $q$ (GSFGPM). 4. Head, dorsal view. 5. Mesoscutum and scutellum. 6. Mesosoma, lateral view. 7. Areolet. 
gray setae. Mesopleuron (Fig. 6) with dense irregular punctures, distance between punctures $0.2-1.5 \times$ diameter of puncture; lower and anterior portions with relative long gray-brown setae; upper-posterior portion largely smooth and shiny. Upper end of epicnemial carina approximately reaching to 0.5 distance to subalar prominence, distant from front margin of mesopleuron. Metapleuron slightly convex, with dense indistinct punctures and long gray-brown setae. Submetapleural carina complete, strong. Wings slightly brownish, hyaline. Fore wing with vein $1 \mathrm{cu}-\mathrm{a}$ distal to $1 / \mathrm{M}$ approximately by $0.4 \times$ length of $1 \mathrm{cu}-\mathrm{a}$. Areolet (Fig. 7) very small, its stalk approximately $1.7 \times$ as long as $2 \mathrm{rs}-\mathrm{m}$, receiving vein $2 \mathrm{~m}$-cu at posterior 0.4 . Vein 2-Cu approximately as long as $2 \mathrm{cu}$-a. Hind wing vein 1 -cu approximately $1.5 \times$ as long as cu-a. Ratio of length of hind tarsomeres from first to fifth approximately: 4.3:2.2:1.7:1.0:1.5. Basal 0.6 of claw pectinate. Median longitudinal carinae of propodeum (Fig. 8) between base and posterior transverse carina parallel; lateral longitudinal carina present. Areas between median longitudinal carinae and area petiolaris smooth, with indistinct irregular wrinkles. Remainder of propodeum with relatively sparse, shallow punctures. Propodeal spiracle circular.

Metasoma. First tergite (Figs 9-10) approximately $1.9 \times$ as long as posterior width, evenly narrowed anteriorly, with distinct fine punctures; spiracle circular, small, located approximately at middle of first tergite. Second tergite (Fig. 10) approximately $0.9 \times$ as long as apical width, almost shiny, with even,
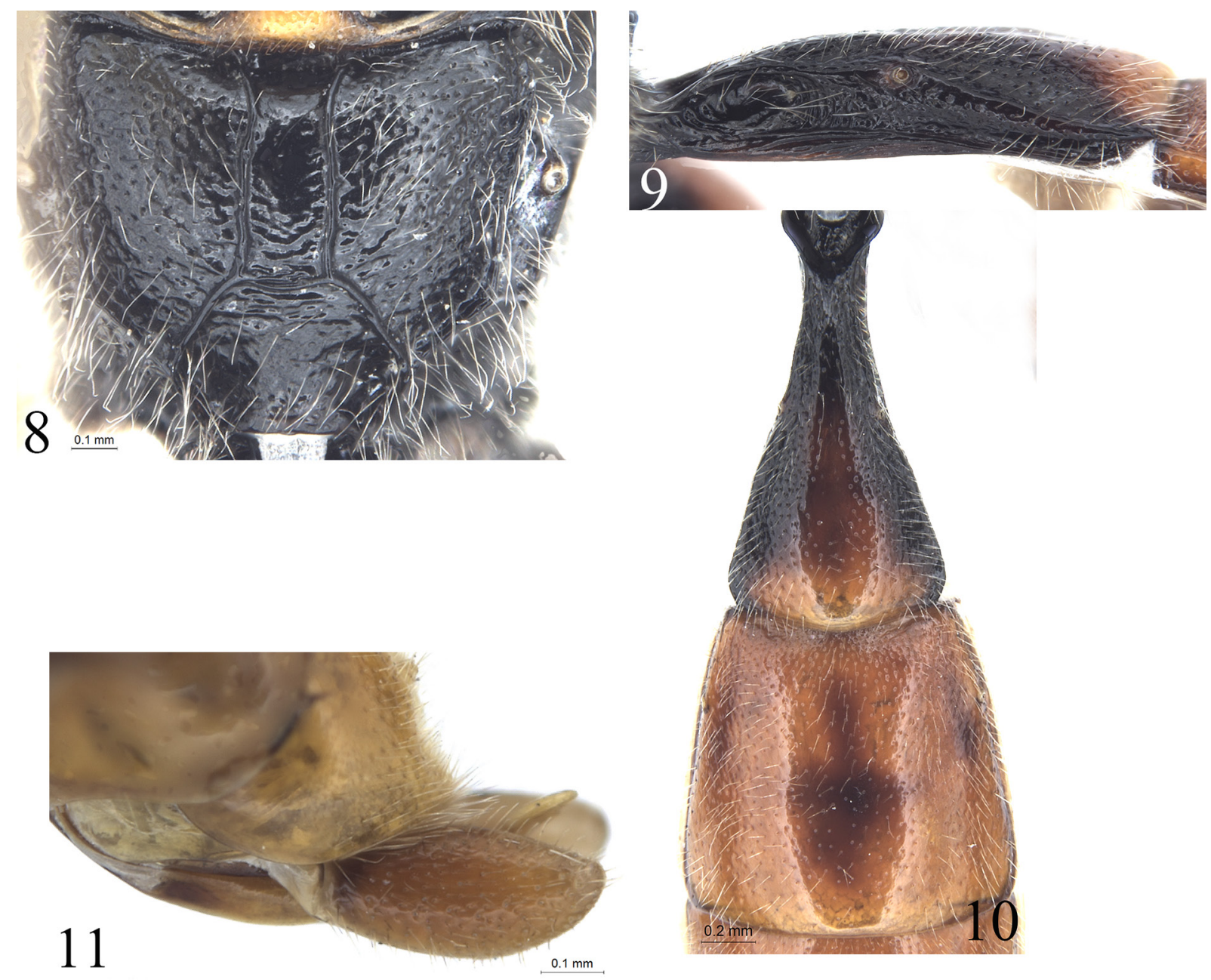

Figs 8-11. Ctenopelma labiatum Sheng, Sun \& Li sp. nov., holotype, $q$ (GSFGPM). 8. Propodeum. 9. First tergite, lateral view. 10. Tergites 1-2, dorsal view. 11. Apical portion of metasoma, lateral view. 
fine punctures and short gray setae. Tergites 3 and 4 with sparse fine punctures. Fifth and subsequent tergites indistinctly punctate. Dorsoposterior portions of tergites 7- 8 largely concave. Ovipositor sheath (Fig. 11) wide, short, approximately $2 \times$ as long as its width, evenly and strongly narrowed posteriorly.

Coloration (Fig. 1). Black, except the following: clypeus except basal margin, mandible except base and teeth, maxillary palpi, labial palpi, tegulae, fore and middle legs except coxae, all yellowish white to brownish yellow; antennae except apical portions, upper-posterior corner of pronotum, scutellum, postscutellum and tergite 8 , all yellowish to reddish brown; apical and dorsal portions of all coxae more or less brownish red; hind trochanters, femora, tibiae and basal tarsomere brown; apical margin of first tergite, second and subsequent tergites all yellowish brown with uneven, slightly dark brown portion; pterostigma brown; ovipositor sheath red-brown.

\section{Differential diagnosis}

The new species can easily be distinguished from other species of Ctenopelma by the following combinations of characters: labium large, ligula long and conspicuously exposed below mandible; areolet very small, with long stalk $(1.7 \times$ as long as height of areolet); median longitudinal carina of propodeum (between posterior transverse carina and anterior margin) parallel; basal 0.6 of claw pectinate.

Ctenopelma lapponica Holmgren, 1857 is also with areolet very small, but claws entirely pectinate in both sexes; posterior tergites of metasoma, hind coxa, trochanter and femur entirely black. The new species with second and subsequent tergites almost entirely yellow-brown, hind coxa, trochanters and femora almost entirely brown.

\section{Ctenopelma lii Sheng, Sun \& Li sp. nov. urn:1sid:zoobank.org:act:31291D0C-7348-4AFD-83DE-71654DA13CB2}

Figs $12-23$

\section{Diagnosis}

Median portion of vertex behind lateral ocelli abruptly steep. Areolet with long stalk. Propodeum (Fig. 19) smooth, shiny, with sparse brown setae; combined areae of area basalis and area petiolaris $2.2 \times$ as long as apical width, slightly narrowed medially. Ovipositor sheath (Fig. 22) $3.6 \times$ as long as its maximum width. Hind coxae, trochanters and femora entirely black.

\section{Etymology}

The new species is named after Tao $\mathrm{Li}$, who collected the type specimen.

\section{Material examined}

\section{Holotype}

CHINA • ; ; Liaoning Province, Kuandian; 27 Jun. 2016; Tao Li leg.; GSFGPM.

\section{Description}

\section{Female}

MEASUREMENTS. Body length approximately $8.5 \mathrm{~mm}$. Fore wing length approximately $7.5 \mathrm{~mm}$. Ovipositor sheath length approximately $0.9 \mathrm{~mm}$.

HEAD. Face (Fig. 13) approximately $1.4 \times$ as wide as long, slightly convex medially, with dense fine punctures and sparse short brown setae; between antennal socket and inner margin of eye with distinct longitudinal groove. Clypeal suture distinct. Clypeus approximately $2.6 \times$ as wide as long, almost smooth, shiny, with sparse brown setae; median portion transversely concave; with dense, transverse 
wrinkles; subapical margin ridge-shape convex; median portion of apical margin almost truncate, sublateral blunted angular. Mandible strong, with brown setae; lower tooth slightly shorter than upper tooth. Malar space at most $0.2 \times$ as long as basal width of mandible. Gena (Fig. 14) smooth, shiny, with sparse brown setae, upper portion convergent backwardly. Vertex (Fig. 15) and frons with texture as that of gena. Median portion of vertex behind lateral ocelli abruptly steep ventrally. Postocellar line approximately $0.8 \times$ as long as ocular-ocellar line. Antenna with 33 flagellomeres; ratio of length from

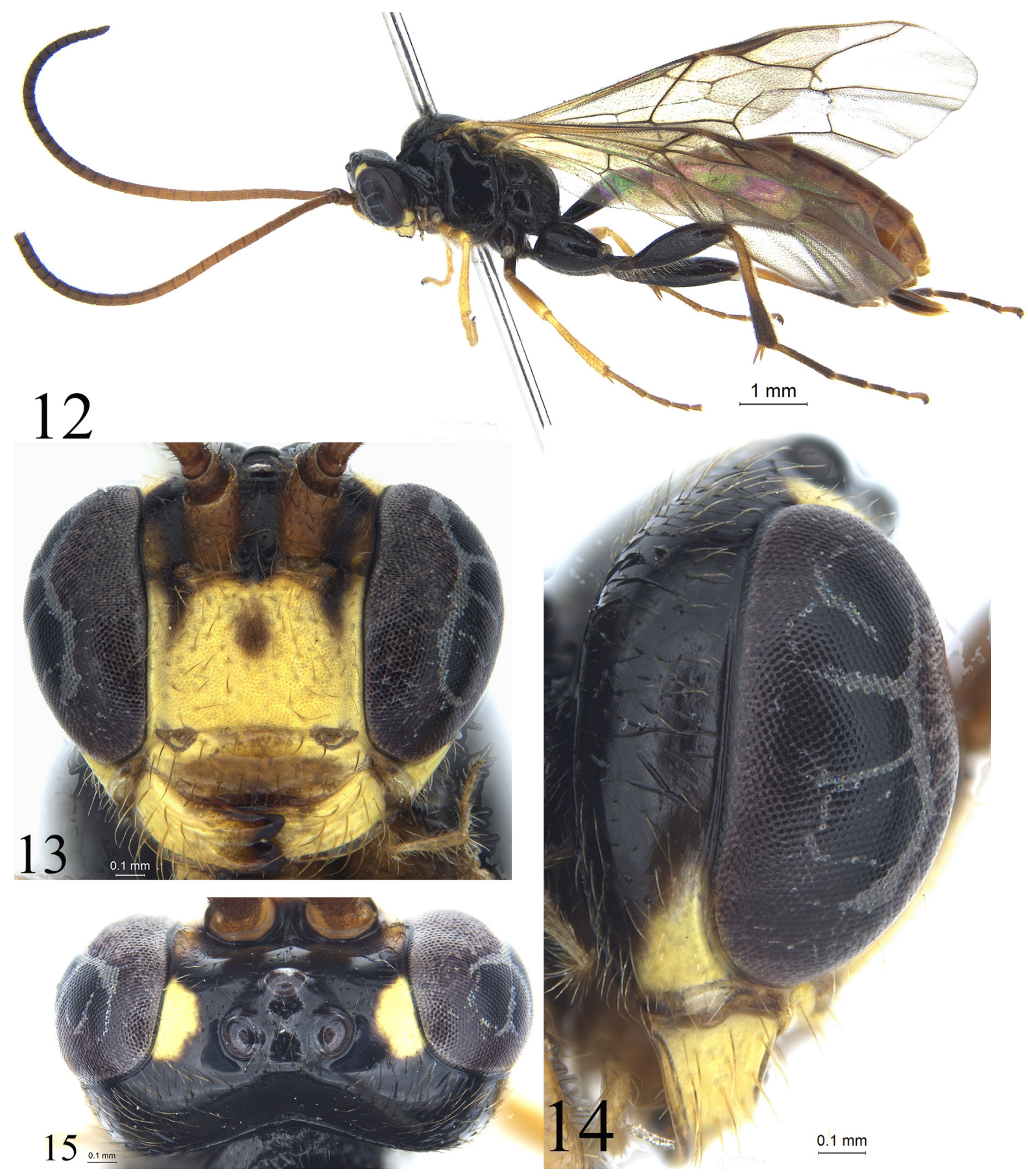

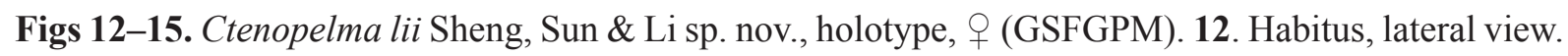
13. Head, anterior view. 14. Head, lateral view. 15. Head, dorsal view. 


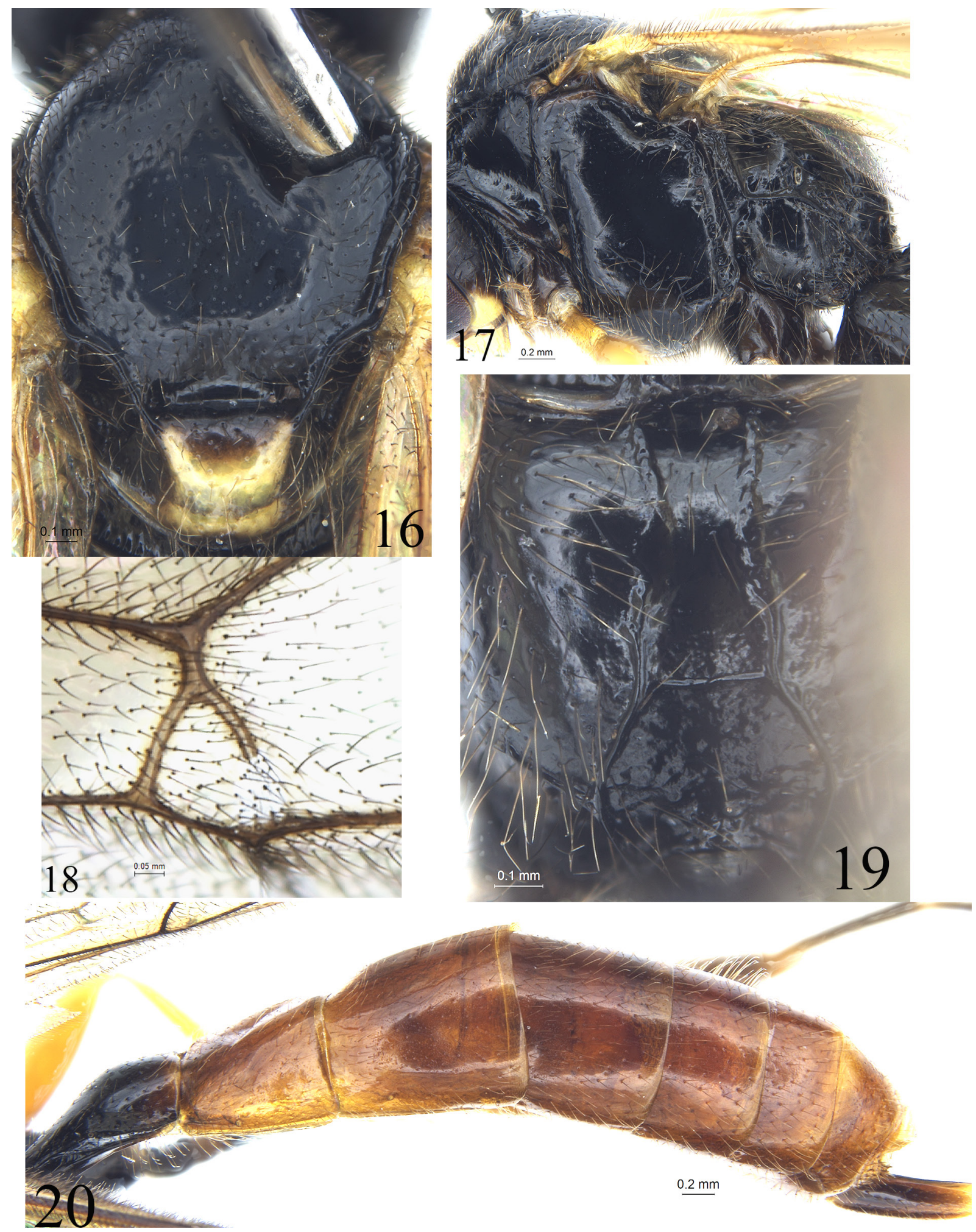

Figs 16-20. Ctenopelma lii Sheng, Sun \& Li sp. nov., holotype, $ๆ$ (GSFGPM). 16. Mesoscutum and scutellum. 17. Mesosoma, lateral view. 18. Areolet. 19. Propodeum. 20. Metasoma, lateral view. 
first to fifth flagellomeres approximately: 2.4:1.6:1.5:1.4:1.3. Occipital carina complete, lower end reaching to base of mandible.

Mesosoma. Pronotum almost smooth, shiny, upper-posterior portion with indistinct, sparse, fine punctures. Epomia weak and short. Mesoscutum and scutellum (Fig. 16) with sparse, fine punctures and brown setae. Anterior portion of notaulus present. Scutoscutellar groove smooth, shiny. Postscutellum with denser punctures than scutellum. Mesopleuron (Fig. 17) smooth, shiny; upper and lower portions with sparse fine punctures and long brown setae. Epicnemial carina thin, upper end approximately reaching to 0.7 distance to subalar prominence. Metapleuron shiny, slightly convex, with sparse fine punctures and long brown setae. Juxtacoxal carina absent. Wings slightly brownish, hyaline. Fore wing with vein $1 \mathrm{cu}-\mathrm{a}$ distal to $1 / \mathrm{M}$ approximately by $0.4 \times$ length of $1 \mathrm{cu}-\mathrm{a}$. Areolet (Fig. 18) almost triangular, its stalk approximately $0.4 \times$ as long as $2 \mathrm{rs}-\mathrm{m}$, receiving vein $2 \mathrm{~m}$-cu approximately $0.75 \times$ distance from vein 2 rs-m to 3 rs-m. 2-Cu approximately $1.5 \times$ as long as $2 \mathrm{cu}-\mathrm{a}$. Hind wing vein 1-cu approximately $1.5 \times$ as long as cu-a. Ratio of length of hind tarsomeres from first to fifth approximately: 5.2:2.6:2.0:1.3:1.5. Claw finely pectinate. Propodeum (Fig. 19) evenly convex, smooth, shiny, with sparse brown setae; area petiolaris with indistinct fine wrinkles; anterior transverse carina and basal portion of lateral longitudinal carina absent. Area basalis and area superomedia combined. Propodeal spiracle oval, distance to lateral longitudinal carina longer than to pleural carina.

Metasoma (Figs 20-22). Tergites almost smooth, shiny, with sparse fine punctures and brown setae. First tergite $2.5 \times$ as long as apical width, with large basal median concavity; median dorsal carinae almost entirely absent; dorsolateral carina from spiracle to anterior margin complete; ventrolateral carina complete. Spiracle circular, small, located approximately at posterior 0.4 of first tergite. Second tergite approximately as long as its posterior width. Fourth tergite as long as wide, lateral sides approximately parallel. Ovipositor sheath (Fig. 22) $3.6 \times$ as long as its maximum width. Ovipositor (Fig. 23) with distinct subapical dorsal notch.

Coloration (Fig. 12). Black, except for following: antenna reddish brown, apical portion brownish black; face except upper lateral longitudinal spots and upper median small spot brownish black; clypeus except most apical median portion brown; mandible except teeth, malar area, upper-anterior portion of
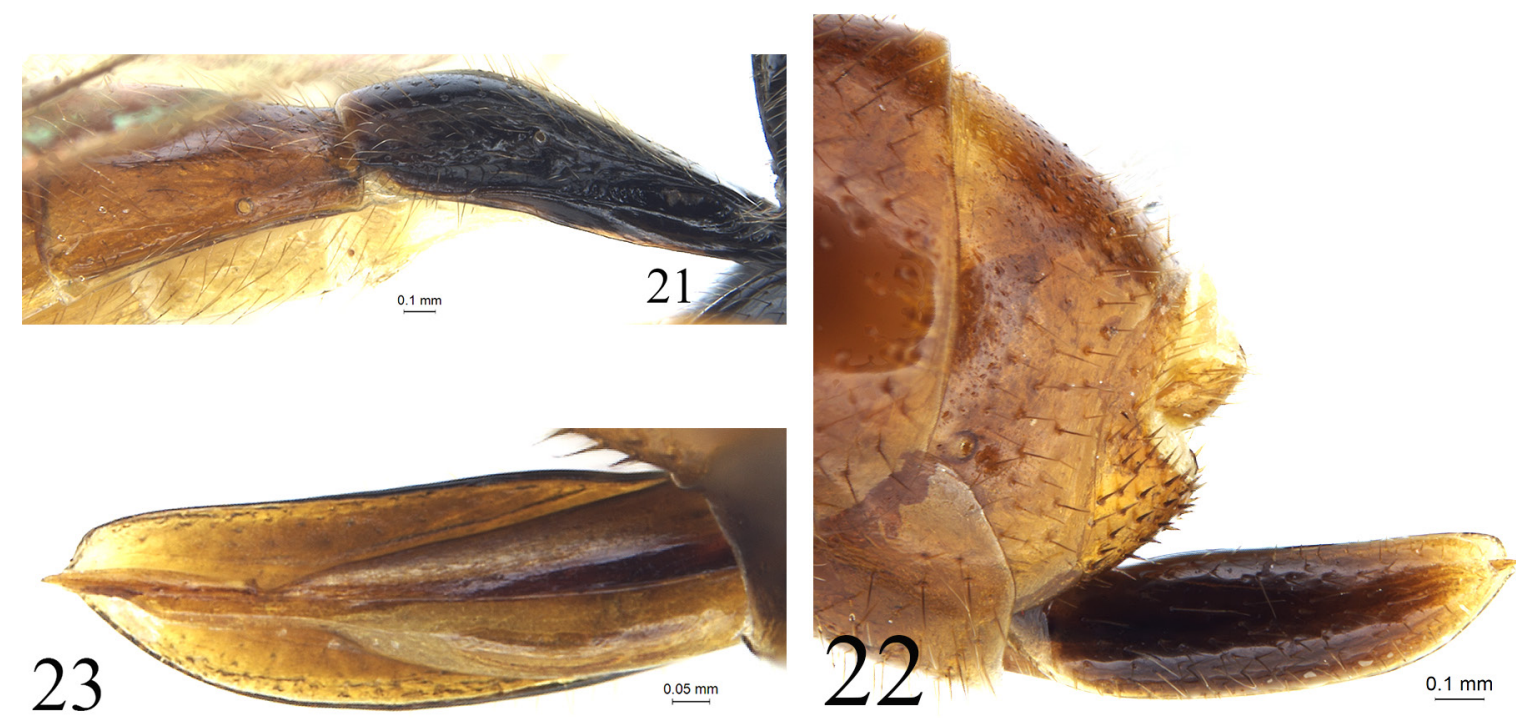

Figs 21-23. Ctenopelma lii Sheng, Sun \& Li sp. nov., holotype, $q$ (GSFGPM). 21. Tergites 1-2, lateral view. 22. Apical portion of metasoma, lateral view. 23. Ovipositor, lateral view. 
gena, part of tegula irregularly, posterior portion of scutellum, postscutellum, apical portions of fore and middle femora, fore and middle tibiae, all yellow; maxillary and labial palpi, upper-posterior corner of pronotum, ventral profile of fore coxa, basal portions of fore and middle femora and hind tibia, basal ends of hind tarsomeres and tergites 2 to 8 reddish brown. Ovipositor sheath brownish black.

\section{Differential diagnosis}

The new species is similar to C. melanothoracicum Sheng, 2009, but can be distinguished from the latter by the following combinations of characters: median portion of vertex behind lateral ocelli abruptly steep ventrally; first tergite $2.5 \times$ as long as apical width; all coxae, hind trochanter and femur black. Ctenopelma melanothoracicum: median portion of vertex behind lateral ocelli evenly convergent ventrally; first tergite $2.1 \times$ as long as apical width; all coxae, hind trochanter and femur red-brown.

\section{Ctenopelma lucifer (Gravenhorst, 1829)}

Mesochorus lucifer Gravenhorst, 1829: 963.

Ctenopelma luciferum (Gravenhorst, 1829) - Sheng \& Sun, 2009: 121.

\section{Material examined}

CHINA - Liaoning Prov. • 1 q; Kuandian, Baishilazi National Natural Reserve; alt. 400 m; 1 Jun. 2001; Mao-Ling Sheng leg. • 1 क; Xinbin; 26 Aug. 2009; interception trap. - Shanxi Prov. • 1 \%; Qinyuan; 3 Jun. 1997; Mao-Ling Sheng leg. -2 웅, 5 ổ; Pinglu; alt. 965 m; 30 Apr.-7 May 2012; reared from cocoons of Acantholyda posticalis (Matsumura, 1912) by Tao Li. - Henan Prov. 5 q $ᄋ$; Lushi; 13-28 Jun. 2008; reared from cocoons of A. posticalis (Matsumura, 1912) by Mao-Ling Sheng - 10 우, 14 त̂̉; Lingbao; alt. 600 m; 29 Apr-11 May 2012; reared from cocoons of A. posticalis (Matsumura, 1912) by Tao Li.

\section{Host}

Acantholyda posticalis (Matsumura, 1912).

Ctenopelma rufofasciatum Sheng, Sun \& Li sp. nov. urn:1sid:zoobank.org:act:A1D0F425-F3DA-4C60-8CC0-5BF50ED5CF62

Figs 24-34

\section{Diagnosis}

Scutellum (Fig. 28), lower portion of mesopleuron (Fig. 29) and propodeum with relatively long gray setae. Propodeum (Fig. 31) shiny, with distinct fine punctures, areae superomedia and petiolaris strongly roughened; anterior portion of area petiolaris with transverse wrinkles. Ovipositor sheath (Figs 24, 34) approximately $10 \times$ as long as its maximum width. Apical portions of wings slightly darkened. Head and mesosoma (Fig. 24) almost entirely black. Tergite 3 red (Fig. 32).

\section{Etymology}

The name of the new species is based on the metasoma having one red tergite.

\section{Material examined}

\section{Holotype}

CHINA • P ; Beijing, Mentougou; 30 Jun. 2011; reared from 'cocoon' (chamber) of Cephalcia lariciphila (Wachtl, 1898) by Tao Li; GSFGPM. 


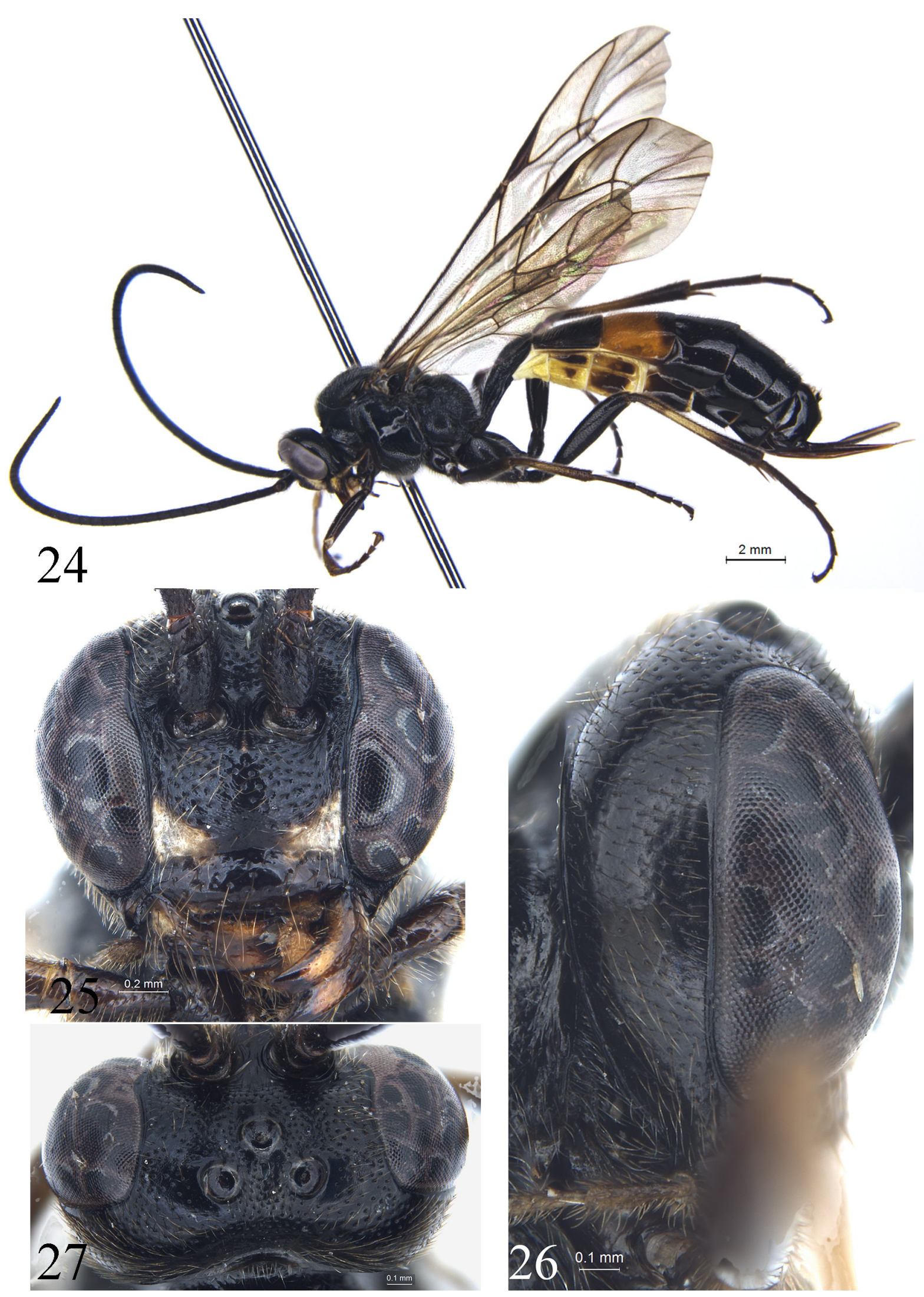

Figs 24-27. Ctenopelma rufofasciatum Sheng, Sun \& Li sp. nov., holotype, $q$ (GSFGPM). 24. Habitus, lateral view. 25. Head, anterior view. 26. Head, lateral view. 27. Head, dorsal view. 


\section{Paratypes}

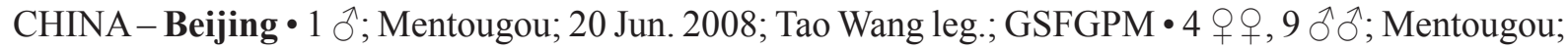
9-30 Jun. 2009; Tao Wang leg.; collected in forest of Larix principis-rupprechtii Mayr; GSFGPM •

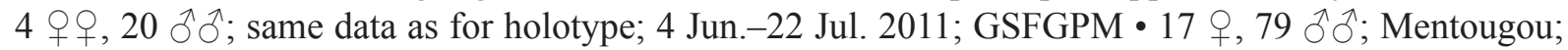
2 Jun.-7 Jul. 2012; Shi-Xiang Zong leg.; collected in forest of L. principis-rupprechtii Mayr; GSFGPM

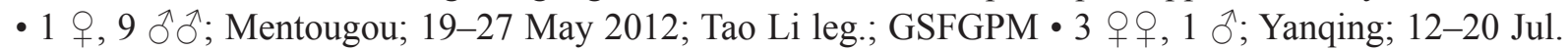
2013; Shi-Xiang Zong leg.; collected in forest of Pinus tabuliformis Carrière; GSFGPM • 1 + ; Yanqing; 16 Jul. 2014; Shi-Xiang Zong leg.; GSFGPM.

\section{Description}

\section{Female}

MeAsurements. Body length 8.0-11.0 mm. Fore wing length approximately $8.0-10.0 \mathrm{~mm}$. Ovipositor sheath length approximately $1.4 \mathrm{~mm}$.

HEaD. Face (Fig. 25) approximately $1.8 \times$ as wide as long, strongly convex, with distinct punctures, distance between punctures 1.0-3.0 $\times$ diameter of puncture; lower median portion with indistinct transverse wrinkles. Clypeus approximately $3.0 \times$ as wide as long, smooth, almost shiny, with sparse punctures and long brown setae; apical margin approximately truncate. Mandible with long brown setae, upper tooth as long as lower tooth. Malar area slightly, indistinctly granulose. Malar space approximately $0.20 \times$ as long as basal width of mandible. Gena (Fig. 26) almost smooth, with sparse, fine punctures, obviously evenly convergent posteriorly. Vertex (Fig. 27) with uneven fine punctures. Interocellar area with relatively dense punctures. Postocellar line $0.8 \times$ as long as ocular-ocellar line. Antenna with 42 flagellomeres. Ratio of length from first to fifth flagellomeres: 6.0:4.0:3.5:3.5:3.5. Occipital carina complete, lower end reaching base of mandible.

Mesosoma. Lateral concavity of pronotum with weak transverse wrinkles, upper-posterior portion with sparse fine punctures. Mesoscutum (Fig. 28) with distinct punctures, distance between punctures 0.5$3.0 \times$ diameter of puncture. Notaulus vestigial. Scutellum slightly convex, with sparse fine punctures and long gray-brown setae. Mesopleuron (Fig. 29) with uneven fine punctures, in lower portion of speculum largely smooth, shiny. Speculum with sparse punctures. Upper end of epicnemial carina reaching to 0.6-height of front margin of mesopleuron. Metapleuron slightly convex, with even fine punctures. Submetapleural carina complete, strong. Wings slightly brownish, hyaline. Fore wing (Fig. 30) with vein $1 \mathrm{cu}-\mathrm{c}$ distal to $1 / \mathrm{M}$ approximately by $0.3 \times$ length of $1 \mathrm{cu}-\mathrm{c}$. Areolet without or with short stalk, receiving vein $2 \mathrm{~m}$-cu approximately $0.5 \times$ distance from vein 2 rs- $\mathrm{m}$ to $3 \mathrm{rs}-\mathrm{m}$. 2 -Cu approximately $1.5 \times$ as long as 2cu-a. Hind wing vein 1-cu 1.5-2.0 $\times$ as long as cu-a. Ratio of length of hind tarsomeres from first to fifth approximately: 17.0:8.0:6.0:3.5:5.0. Propodeum (Fig. 31) evenly convex, with distinct punctures; area superomedia and area petiolaris confluent, strongly roughened; anterior portion of area petiolaris with indistinct transverse wrinkles. Propodeal spiracle oval.

Metasoma. First tergite (Figs 32-33) 2.6-2.7 $\times$ as long as posterior width. Postpetiole with weak sparse punctures. Spiracle circular, located at apical 0.4 of first tergite approximately. Second tergite approximately $0.9 \times$ as long as posterior width. Ovipositor sheath approximately $10 \times$ as long as its maximum width. Ovipositor (Fig. 34) evenly, strongly narrowed apically, with distinct subapical dorsal notch.

Coloration (Fig. 24). Black, except following; lower lateral portion of face white; median portions of mandibles yellowish brown; maxillary and labial palpi, apical portions of fore femur, fore tibia, median portion of middle tibia and apical portion of hind femur yellow-brown; hind tarsus blackish brown; third tergite entirely or anterior half red; pterostigma and veins brownish black. 
SUN S.-P. et al., The species of Ctenopelma Holmgren from China

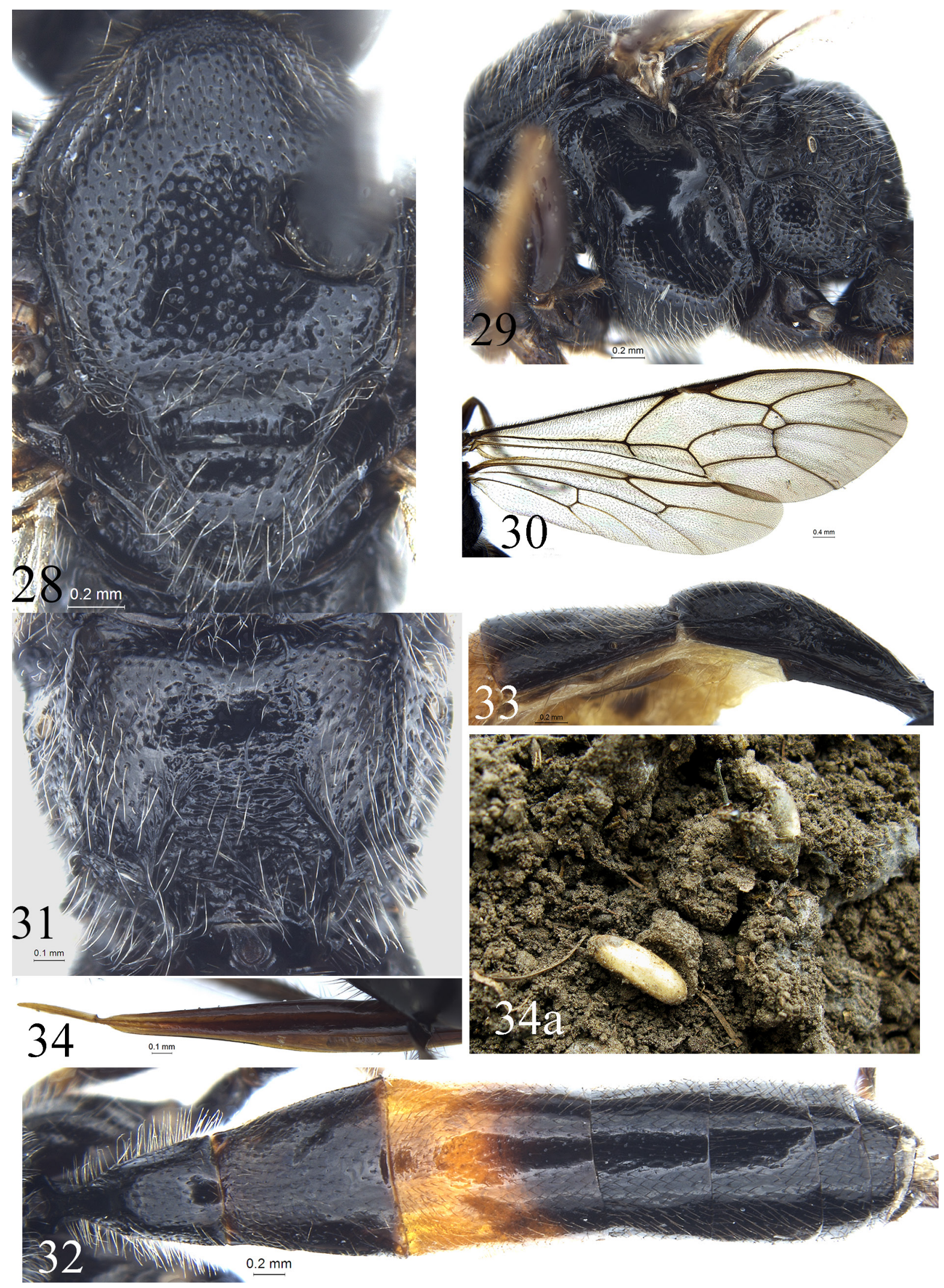

Figs 28-34. Ctenopelma rufofasciatum Sheng, Sun \& Li sp. nov., holotype, + (GSFGPM). 28. Mesoscutum and scutellum. 29. Mesosoma, lateral view. 30. Wings. 31. Propodeum. 32. Metasoma, dorsal view. 33. Ttergites 1-2, lateral view. 34. Ovipositor, lateral view. 34a. Cocoon. 


\section{Male}

Antenna with 43 flagellomeres. Median portions of mandibles, maxillary and labial palpi, fore and middle tibiae and tarsi and hind tibiae except apical portions yellow.

\section{Host}

One female of Ctenopelma rufofasciatum was reared from a 'cocoon' (chamber) of Cephalcia lariciphila (Wacht1, 1898) by Tao Li from Mentougou, Beijing.

\section{Host foodplant}

Larix principis-rupprechtii Mayr.

\section{Differential diagnosis}

According to the most recent revision of Ctenopelma from the Palaearctic (Kasparyan 2004), the new species belongs to the $C$. lucifer subgroup in having gena convergent posteriorly, gena and mesosoma distinctly punctate, area superomedia separated from area petiolaris (but the new species is confluent) and ovipositor sheath longer. The new species can be easily dinstinguished from the only known species of the lucifer subgroup, C. lucifer (Gravenhorst, 1829), by the following combination of characters: area superomedia and area petiolaris confluent; anterior portion of median longitudinal carina of propodeum obliterated; face black, lower lateral portion with large white spots; frons and vertex entirely black; hind coxa, trochanter and femur entirely black; third tergite red. Ctenopelma lucifer: area superomedia separated from area petiolaris by carina; median longitudinal carina of propodeum complete and strong; face entirely yellow-brown; frons and vertex with laterally yellowish brown spots; hind coxa, trochanter and femur brown to darkish brown; tergites 2-4 red-brown.

\section{Material examined}

\section{Ctenopelma nigrum Holmgren, 1857}

CHINA • 1 q; Beijing, Mentougou; 25 May 2009; reared from 'cocoon' (chamber) of Cephalcia

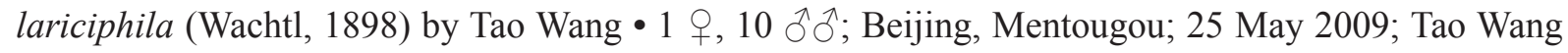
and Shi-Xiang Zong leg.; collected in forest of Larix principis-rupprechtii Mayr.

\section{Host}

Cephalcia lariciphila (Wachtl, 1898).

\section{Host foodplant}

Larix principis-rupprechtii Mayr.

\section{Remarks}

New record for China.

Ctenopelma pineatum Sheng, Sun \& Li sp. nov. urn:1sid:zoobank.org:act:BF6D5A2C-662E-449B-A6D0-E0BB79DCBBF6

Figs $35-42$

\section{Diagnosis}

Antenna with at least 50-segmented flagellum and about setiform apex. Second and third tergites longer than their posterior width. Anterior half of second tergite strongly irregularly rugose, posterior half almost smooth, shiny, with distinct punctures. Ovipositor sheath (Fig. 42) approximately $2.5 \times$ as long 
as wide, along lower margin with distinct parallel groove. Head (almost entirely), mesosoma, metasoma, hind leg, and ovipositor sheath black.

\section{Etymology}

The name of the new species is based on the host plant's name.

\section{Material examined}

\section{Holotype}

CHINA • P; Henan Province, Lushi, Dongwan Forest Farm; alt. 1214 m; 13 Apr. 2012; reared from cocoon of Acantholyda posticalis (Matsumura, 1912) by Tao Li; GSFGPM.

\section{Paratypes}

CHINA - Heilongjiang Prov. 1 क; Linkou; 13 Jul. 2003; GSFGPM. - Henan Prov. 1 o; Lingbao; alt. 1059 m; 22 May 2004; reared from cocoon of Acantholyda posticalis (Matsumura, 1912) by MaoLing Sheng; GSFGPM • 1 \%; Lingbao; 10 May 2008; reared from cocoon of A. posticalis (Matsumura, 1912) by Mao-Ling Sheng; GSFGPM • 1 क; Lushi; 22 May 2008; reared from cocoon of A. posticalis

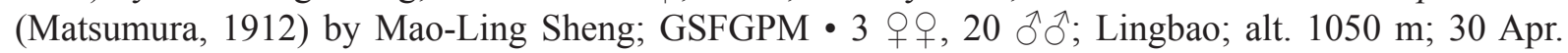
2009; reared from cocoons of A. posticalis (Matsumura, 1912) by Mao-Ling Sheng; GSFGPM • 1 \%; Lingbao; 11 May 2010; Tao Li leg.; GSFGPM. - Beijing • 22 우, 11 ðð; Mentougou; 25 May-9 Jun. 2009; reared from cocoons of Cephalcia lariciphila (Wacht1, 1898) by Tao Wang; GSFGPM • 1 \%; Mentougou; 2 Jun. 2012; Shi-Xiang Zong leg.; GSFGPM. - Shan'xi Prov. • 1 q; Yongshou; 2 Feb. 2010; reared from cocoons of $A$. posticalis (Matsumura, 1912) by Tao Li; GSFGPM. - Jilin Prov. •

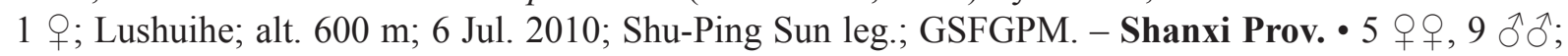
Pinglu; alt. 965 m; 14-18 Apr. 2012; reared from cocoons of A. posticalis (Matsumura, 1912) by Tao Li; GSFGPM. - Liaoning Prov.•1 O; Kuandian; alt. 600 m, 16 Jun. 2017; Tao Li leg.; GSFGPM.

\section{Description}

\section{Female}

Measurements. Body length 10.0-13.0 mm. Fore wing length $8.0-10.5 \mathrm{~mm}$. Ovipositor sheath length approximately $0.8 \mathrm{~mm}$.

HEAD. Inner eye margin slightly concave opposite antennal socket. Face (Fig. 36) $1.4-1.6 \times$ as wide as long, strongly convex, alutaceous, with sparse uneven fine punctures. Clypeus approximately $3.0 \times$ as wide as long; transversely convex medialy, smooth; basal portion with texture as that of face; apical portion depressed, smooth. Mandible with sparse punctures and gray setae. Upper tooth almost as long as lower tooth. Malar space very short, approximately $0.1 \times$ as long as basal width of mandible. Gena (Fig. 37) almost smooth, evenly convergent posteriorly, with fine punctures. Vertex (Fig. 38) smooth, shiny, with uneven fine punctures. Postocellar line approximately as long as ocular-ocellar line. Frons almost flat, with median groove. Antenna with 50-54 flagellomeres. Ratio of length from first to fifth flagellomeres: 8.5:6.5:6.0:5.5:5.5. Occipital carina complete, lower end reaching base of mandible.

Mesosoma. Anterior portion of pronotum with indistinct longitudinal lines and fine punctures, lateral concavity along epomia with irregular short oblique wrinkles, upper-posterior portion with distinct, dense, fine punctures. Epomia distinct. Mesoscutum with even, dense fine punctures. Scutellum and postscutellum with punctures almost as mesoscutum. Mesopleuron (Fig. 39) with fine punctures; along posterior margin with transverse wrinkles; median portion smooth, shiny. Upper end of epicnemial carina approximately reaching to 0.4 distance to subalar prominence, distant from front margin of mesopleuron. Metapleuron evenly convex, with fine, almost even punctures. Juxtacoxal carina absent. Submetapleural carina complete, strong. Wings gray-brownish, hyaline. Fore wing with vein $1 \mathrm{cu}-\mathrm{a}$ opposite $1 / \mathrm{M}$. Areolet quadrangular, with short stalk, receiving vein $2 \mathrm{~m}$-cu approximately $0.7 \times$ distance 


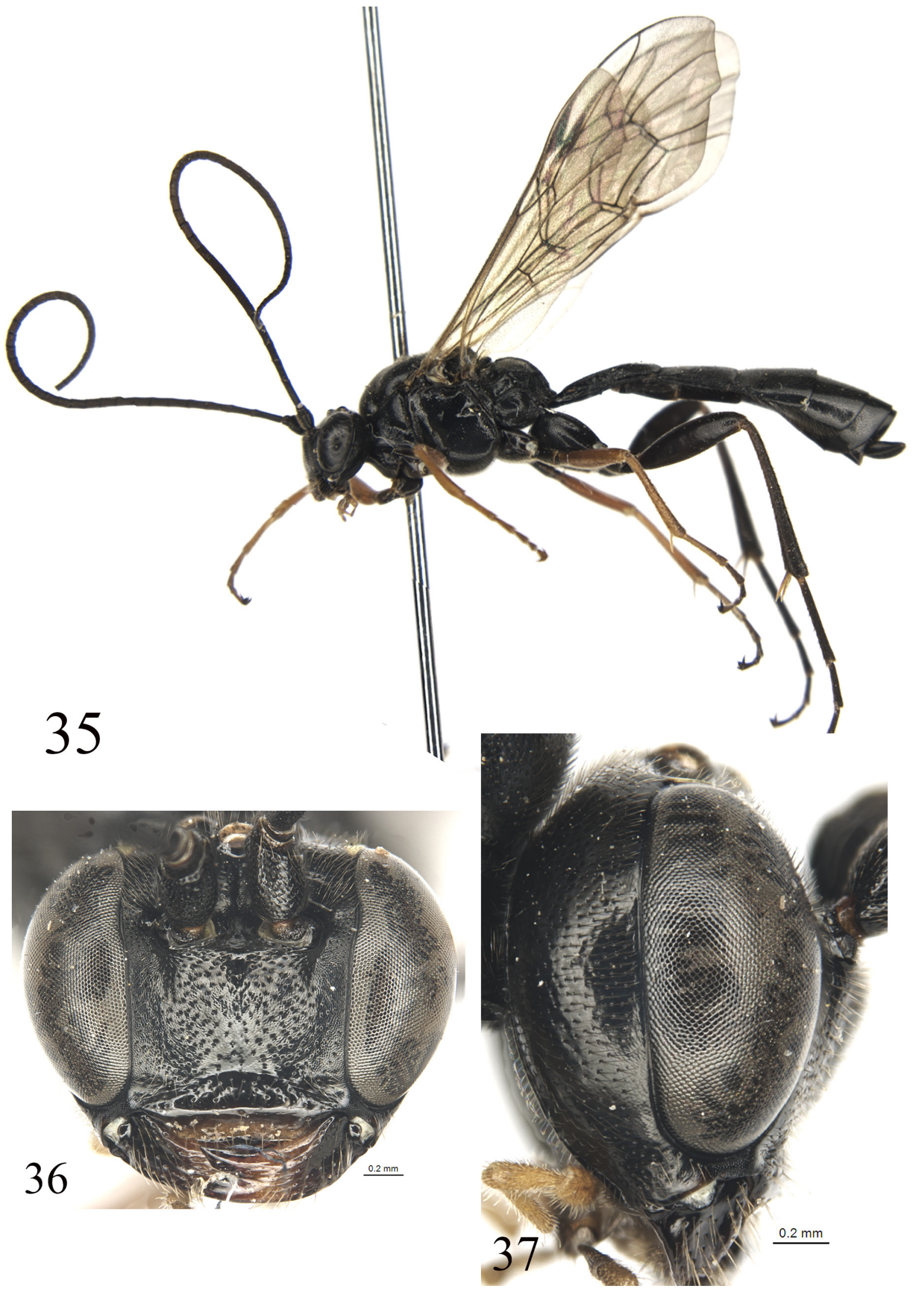

Figs 35-37. Ctenopelma pineatum Sheng, Sun \& Li sp. nov., holotype, $\subsetneq$ (GSFGPM). 35. Habitus, lateral view. 36. Head, anterior view. 37. Head, lateral view. 
from vein 2 rs-m to 3 rs-m. 2-Cu approximately $1.5 \times$ as long as $2 \mathrm{cu}$-a. Hind wing vein 1 -cu shorter than cu-a. Ratio of length of hind tarsomeres from first to fifth approximately: 11.5:6.0:4.0:2.5:3.0. Claw almost simple. Propodeum (Fig. 40) evenly convex; median longitudinal carinae complete, strong; areae basalis, superomedia and petiolaris completely confluent, slightly rough; remaining areas of propodeum with almost even punctures. Propodeal spiracle elongate-oval.

Metasoma (Fig. 41). First tergite approximately $1.7 \times$ as long as posterior width; median dorsal carinae reaching beyond spiracle; dorsolateral and ventrolateral carinae complete; postpetiole with dense fine punctures; spiracle located slightly anterior of middle. Second tergite 1.1-1.2 $\times$ as long as posterior width, anterior half strongly irregularly rugose, posterior half almost smooth, shiny, with distinct

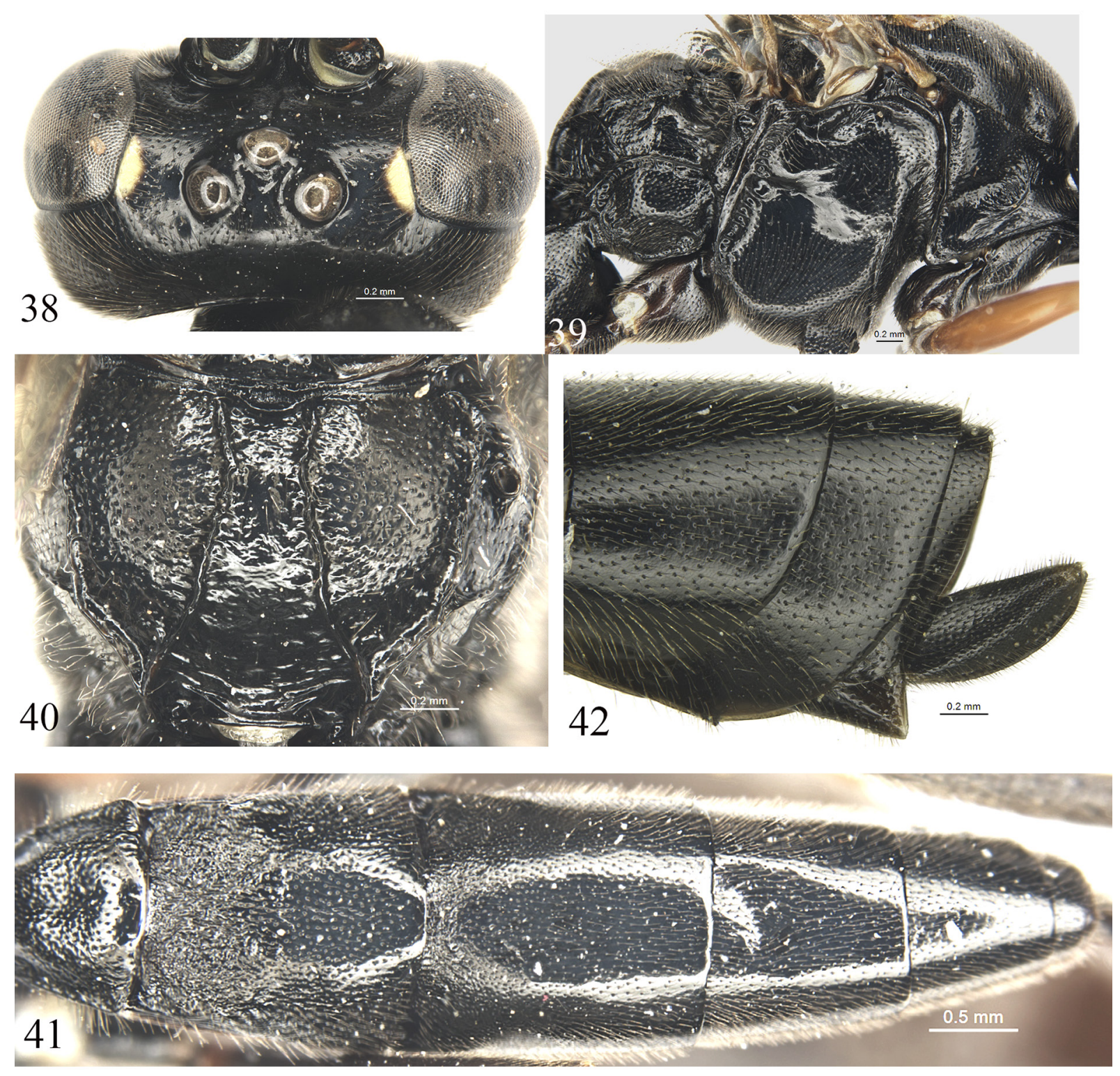

Figs 38-42. Ctenopelma pineatum Sheng, Sun \& Li sp. nov., holotype, ๆ (GSFGPM). 38. Head, dorsal view. 39. Mesosoma, lateral view. 40. Propodeum. 41. Metasoma, dorsal view. 42. Apical portion of metasoma, lateral view. 
punctures. Ovipositor sheath (Fig. 42) approximately $2.5 \times$ as long as wide, knife-shaped, along lower margin with distinct parallel groove.

Coloration (Fig. 35). Black, except following; apical margin of clypeus, median portion of mandible, maxillary and labial palpi, all reddish brown to darkish brown; fore and middle legs, except coxae and trochanters reddish brown; lateral spots of vertex yellow; tegula, pterostigma and veins blackish brown.

\section{Male}

Measurements. Body length 11.0-13.0 mm. Fore wing length $8.0-11.0 \mathrm{~mm}$.

Coloration. Face, clypeus, mandible except teeth and small spots on upper-posterior portion of pronotum yellow; maxillary and labial palpi dark brown; parts of fore and middle coxae, fore and middle trochanters, and tegulae yellowish brown to brown, with remainder of fore and middle legs reddish brown; ventral profiles of hind tibiae, basal portions of hind tarsomeres and apices dark brown.

\section{Hosts}

Acantholyda posticalis (Matsumura, 1912), Cephalcia lariciphila (Wacht1, 1898).

\section{Host foodplants}

Larix principis-rupprechtii Mayr, Pinus tabuliformis Carrière, P. thunbergii Parl.

\section{Differential diagnosis}

The new species is similar to C. altitudinis (Heinrich, 1953), but can be distinguished from the latter by the following combination of characters: fore wing with vein $1 \mathrm{cu}$-a opposite $1 / \mathrm{M}$; hind wing vein 1-cu shorter than cu-a; second tergite about 1.1 to $1.2 \times$ as long as its maximum width; ovipositor sheath (Fig. 42) with distinct parallel groove along lower margin; hind leg and all tergites black. Ctenopelma altitudinis: fore wing with vein $1 \mathrm{cu}-\mathrm{a}$ basad of $1 / \mathrm{M}$; hind wing vein 1-cu distinctly longer than cu-a. second tergite about 0.85 to $9.5 \times$ as long as its maximum width; ovipositor sheath without distinct parallel groove along lower margin; at least basal half of hind femur red-brown; median tergites of metasoma red-brown.

Ctenopelma ruficoxator Aubert, 1987

Ctenopelma ruficoxator Aubert, 1987: 39.

\section{Material examined}

CHINA • 1 क; Zhejiang Prov., Lin'an, Mt. West Tianmu, Xianrending; $30^{\circ} 35^{\prime}$ N, $119^{\circ} 42^{\prime}$ E; alt. 1506 m; 11 May 2018; Ze-Jiang Li \& Meng-Meng Liu leg.

\section{Remarks}

New record for China.

Ctenopelma spiraculare Sheng, Sun \& Li sp. nov. urn:1sid:zoobank.org:act:617516A6-22DF-426D-B320-D00F4F9DD925

Figs $43-53$

\section{Diagnosis}

Upper median portion of occipital carina distinctly flange-shaped. Apical portions of wings slightly darkened. Fore wing with vein $1 \mathrm{cu}-\mathrm{c}$ distal to $1 / \mathrm{M}$ by $0.6 \times$ length of $1 \mathrm{cu}-\mathrm{a}$. Areolet receiving vein $2 \mathrm{~m}$ cu approximately $0.45 \times$ distance from vein 2 rs-m to 3 rs-m; $2-\mathrm{Cu}$ approximately $2.3 \times$ as long as $2 \mathrm{cu}-\mathrm{a}$. 


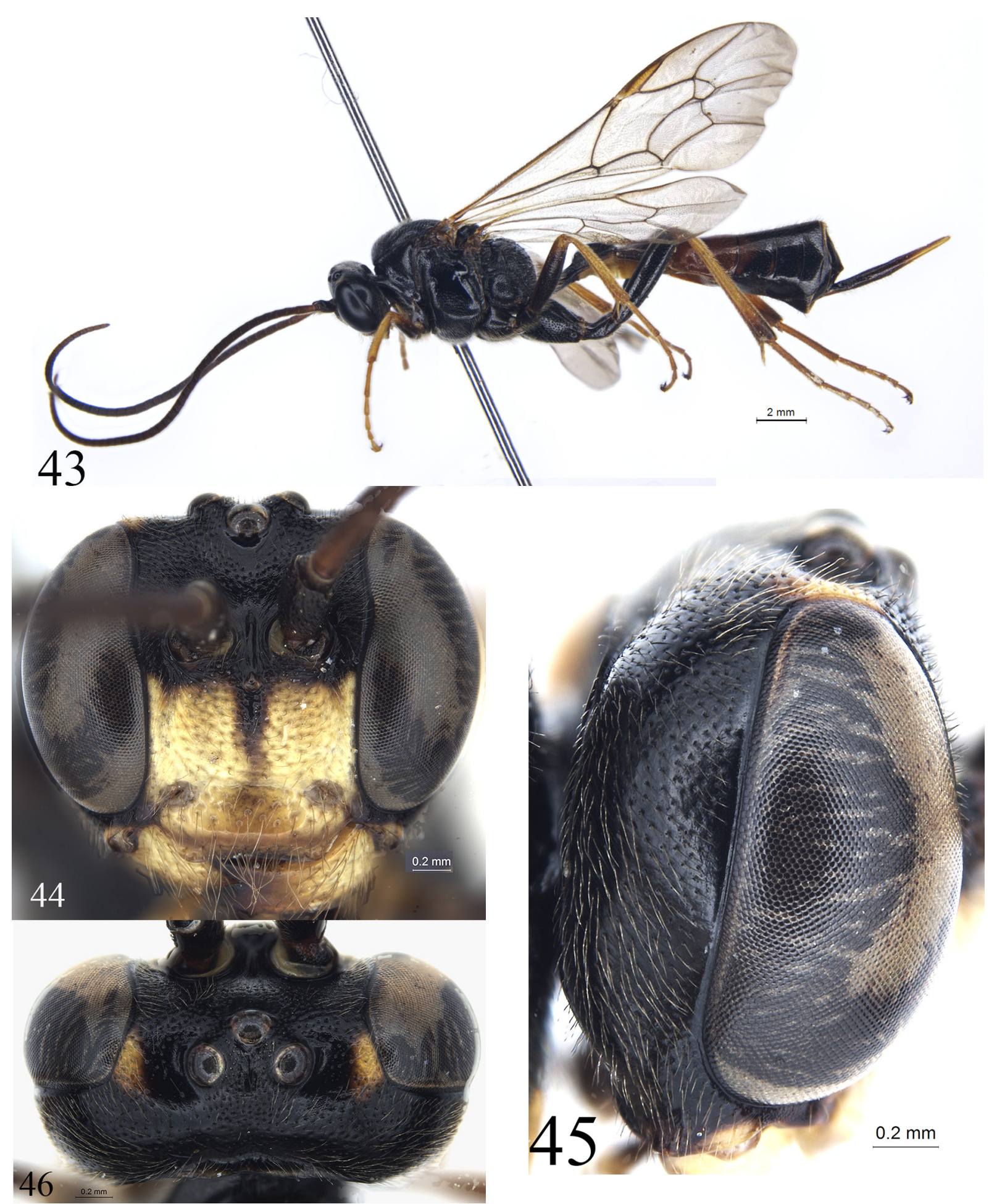

Figs 43-46. Ctenopelma spiraculare Sheng, Sun \& Li sp. nov., holotype, ㅇ (GSFGPM). 43. Habitus, lateral view. 44. Head, anterior view. 45. Head, lateral view. 46. Head, dorsal view. 
First tergite abruptly strongly narrowed anterior of spiracle, spiracle small, strongly convex. Mesosoma, all coxae and hind femora almost entirely black.

\section{Etymology}

The name of the new species is based on the strongly convex spiracle of the first tergite.

\section{Material examined}

\section{Holotype}

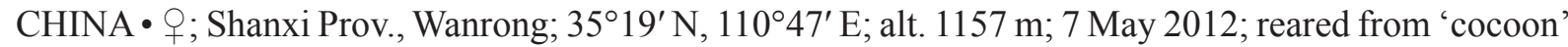
(chamber) of Acantholyda posticalis (Matsumura, 1912) by Tao Li; GSFGPM.

\section{Paratype}

CHINA • 1 क; Henan Prov., Lingbao; alt. 290 m; 11 May 2010; reared from 'cocoon' (chamber) of Acantholyda posticalis (Matsumura, 1912) by Tao Li; GSFGPM.

\section{Description.}

\section{Female}

MEAsurements. Body length 9.3-13.3 mm. Fore wing length $8.0-10.9 \mathrm{~mm}$. Ovipositor sheath length $2.8-3.5 \mathrm{~mm}$.

HEAD. Inner eye margin slightly concave opposite to antennal socket. Face (Fig. 44) approximately $1.7 \times$ as wide as long, evenly convex, almost shiny, with sparse fine punctures and yellowish brown setae; upper margin with a small median tubercle. Clypeus approximately $2.8 \times$ as wide as long; subapical portion transverse convex, smooth, shiny; median portion of apical margin truncate. Mandible with dense, relatively long yellowish brown setae. Upper tooth almost as long as lower tooth. Malar space approximately $0.2 \times$ as long as basal width of mandible. Gena (Fig. 45) almost smooth, evenly convergent posteriorly, with fine punctures and dense gray-brown setae. Vertex (Fig. 46) with sculpture as that of gena. Postocellar line approximately $0.8 \times$ as long as ocular-ocellar line. Frons with fine punctures, between antennal socket with distinct longitudinal carina. Antenna with 43-44 flagellomeres. Ratio of length from first to fifth flagellomeres: 1.7:1.3:1.2:1.1:1.0. Occipital carina complete, upper median portion distinctly flange-shaped, lower end reaching base of mandible.

Mesosoma. Anterior portion of pronotum shiny, with dense, fine punctures; lateral concavity smooth, shiny; dorsoposterior portion with comparatively dense fine punctures. Mesoscutum (Fig. 47) shiny, with weak, uneven punctures. Notaulus indistinct. Scutoscutellar groove wide, relatively deep, smooth, shiny. Scutellum with distinct gray setae and fine, even, relatively sparser punctures than on mesoscutum. Anterior portion of postscutellum deeply concave. Anterior and upper portions of mesopleuron (Fig. 48) with irregular, relatively sparse punctures; lower half with dense punctures, distance between punctures 0.2-2.0 × diameter of puncture; median portion largely smooth, shiny. Upper end of epicnemial carina approximately reaching 0.6 level of front margin of mesopleuron, distant from front margin of mesopleuron. Metapleuron almost shiny, with almost even punctures, distance between punctures 0.5-2.0 $\times$ diameter of puncture. Juxtacoxal carina absent. Submetapleural carina complete, marginate. Wings slightly gray, hyaline, apical portion slightly darkish. Fore wing with vein $1 \mathrm{cu}$-a distal to $1 / \mathrm{M}$ by $0.6 \times$ length of $1 \mathrm{cu}-\mathrm{a}$. Areolet large, obliquely quadrangular, receiving vein $2 \mathrm{~m}$-cu approximately $0.45 \times$ distance from vein 2 rs-m to $3 \mathrm{rs}-\mathrm{m}, 2 \mathrm{rs}-\mathrm{m}$ distinctly shorter than 3rs-m. 2-Cu approximately $2.3 \times$ as long as $2 \mathrm{cu}-\mathrm{a}$. Hind wing vein 1-cu approximately $1.5 \times$ as long as cu-a. Ratio of length of hind tarsomeres from first to fifth approximately: 5.1:2.2:1.7:1.0:1.5. Claw distinctly pectinate. Propodeum (Fig. 49) evenly convex, with relatively dense, long gray setae; median longitudinal carinae behind transverse carina very weak; areae basalis, superomedia and petiolaris completely confluent, with dense transverse 

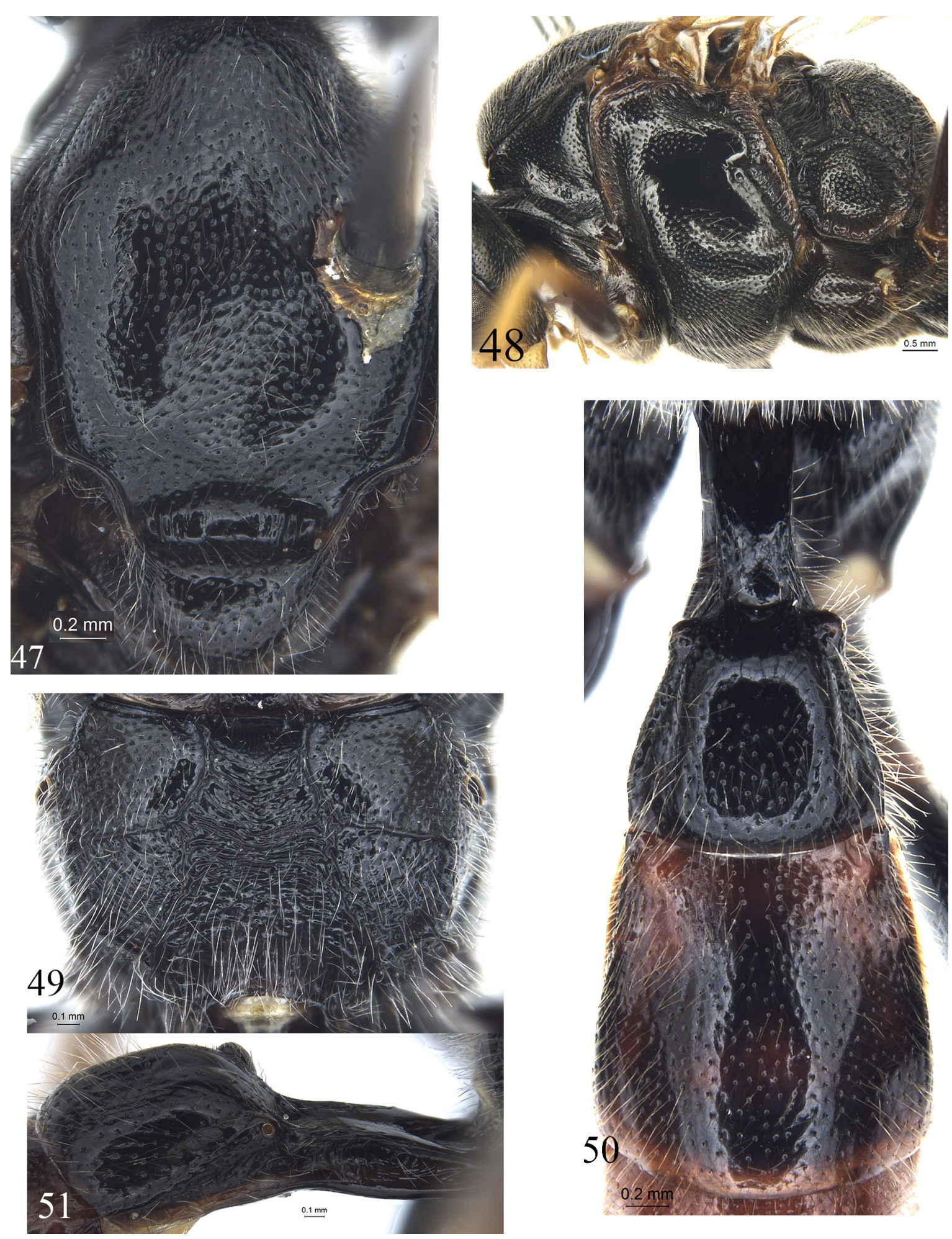

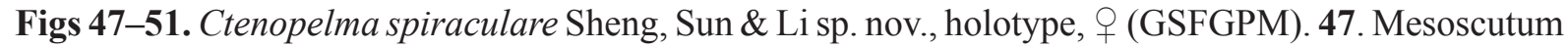
and scutellum. 48. Mesosoma, lateral view. 49. Propodeum. 50. Tergites $1-2$, dorsal view. 51. First tergite, lateral view. 
wrinkles; area dentipara with short, indistinct transverse wrinkles and punctures; remaining areas of propodeum with shallow, almost even punctures. Propodeal spiracle elongate-oval.

Metasoma. Petiole (Figs 50-51) smooth, shiny, lateral sides almost parallel; postpetiole abruptly strongly widened, shiny, with weak punctures, lateral portion with long gray setae; spiracle circular, small, strongly convex. Second tergite (Fig. 50) approximately as long as posterior width, with relatively sparse, fine punctures. Third and subsequent tergites almost shiny, with fine punctures and short brownish gray setae. Ovipositor sheath (Fig. 52) approximately $9.2 \times$ as long as maximum width, $0.8 \times$ as long as hind tibia. Ovipositor evenly narrowed apically, with indistinct dorsal notch.

Coloration (Fig. 43). Black, except following; face except upper margin and median longitudinal spot, clypeus except median yellowish brown portion, mandibles except teeth, all yellowish white; maxillary and labial palpi, lateral spots of vertex, upper posterior corner of pronotum, fore tibia and tarsus, middle tibia, basal 0.7 of hind tibia, basal portions of middle and hind tarsomeres more or less, parts of apical portions of ovipositor sheath, all yellow; part of second tergite irregularly and indistinctly, third tergite and basal margin of fourth tergite red-brown. Tegulae and veins dark brown. Pterostigma yellowish brown.

Cocoon (Fig. 53). Brownish black, with a wide white ring; length approximately $14 \mathrm{~mm}$; diameter approximately $5.2 \mathrm{~mm}$.

\section{Host}

Acantholyda posticalis (Matsumura, 1912).

\section{Host foodplant}

Pinus tabuliformis Carrière.

\section{Differential diagnosis}

The new species can be distinguished from other species of Ctenopelma by the following combinations of characters: first tergite from spiracle abruptly narrowed anteriorly, spiracle strongly convex; postpetiole slightly to strongly convex, length distinctly shorter than its width; second tergite shorter than its posterior width; hind wing vein 1-cu distinctly shorter than cu-a.
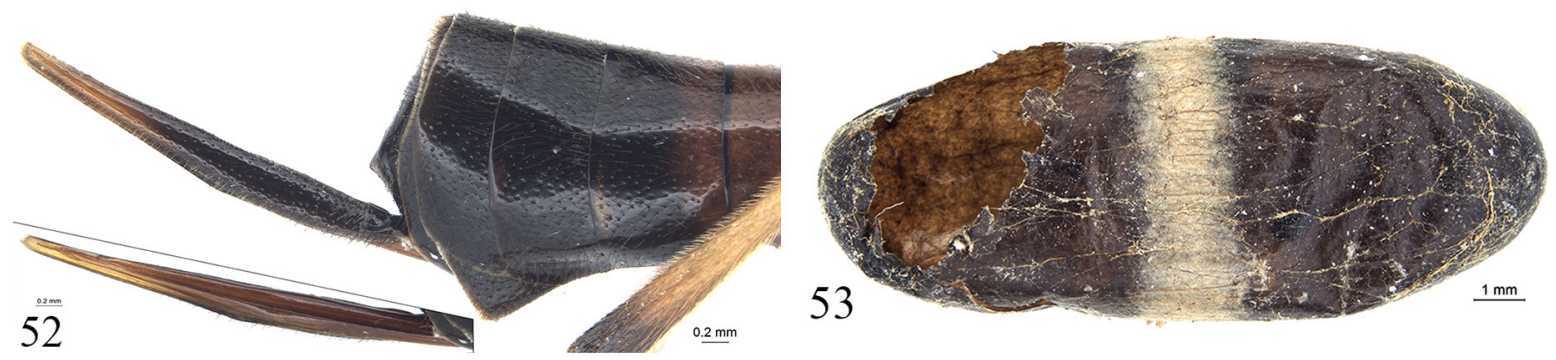

Figs 52-53. Ctenopelma spiraculare Sheng, Sun \& Li sp. nov., holotype, $q$ (GSFGPM). 52. Apical portion of metasoma, lateral view. 53. Cocoon. 
Ctenopelma melanothoracicum Sheng, 2009

Figs 54-56

Ctenopelma melanothoracica Sheng in Sheng \& Sun, 2009: 122.

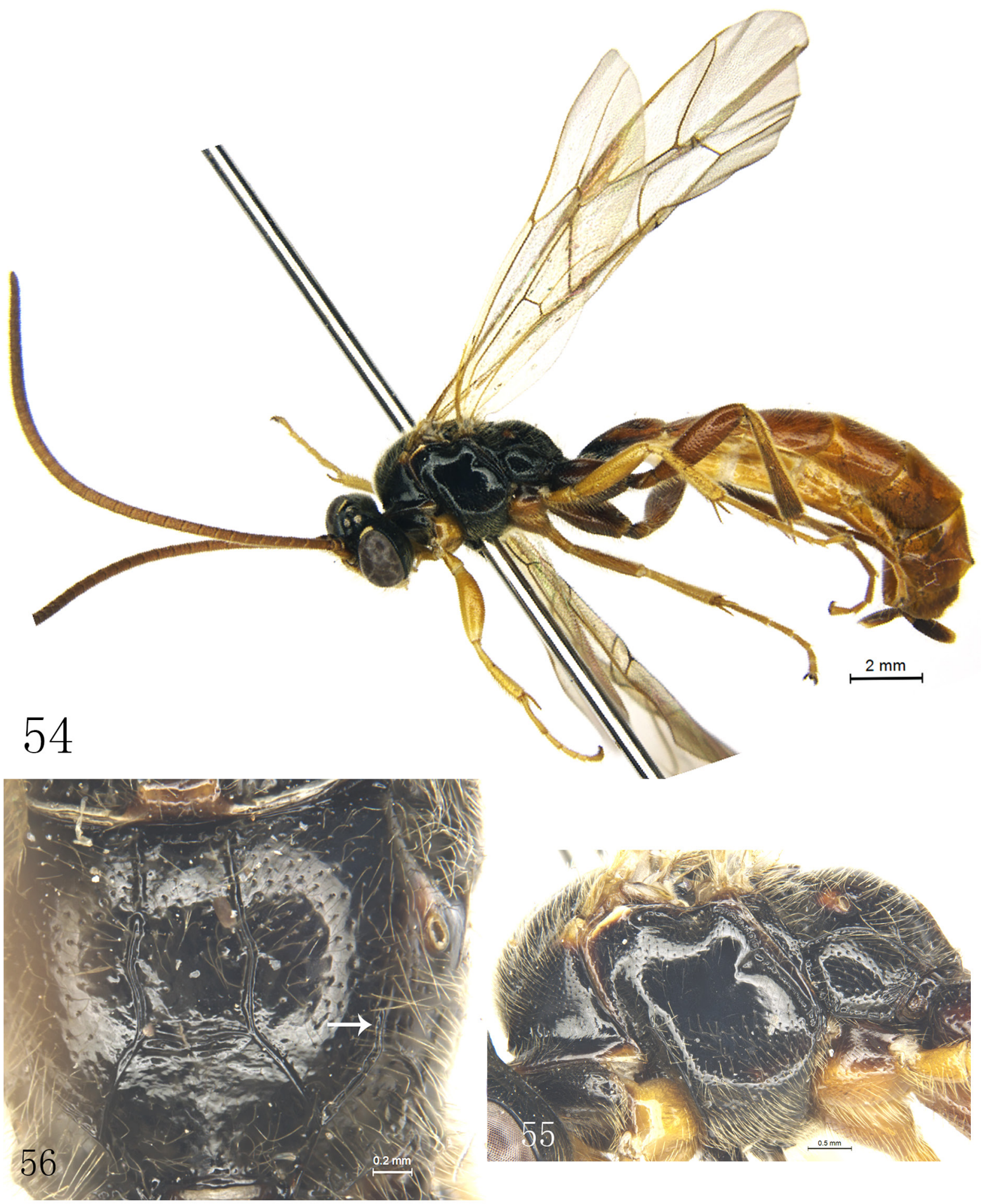

Figs 54-56. Ctenopelma melanothoracicum Sheng, 2009, holotype, $q$ (GSFGPM). 54. Habitus, lateral view. 55. Mesosoma, lateral view. 56. Propodeum. 


\section{Material examined}

CHINA - Henan Prov. 1 क , holotype; Neixiang, Baotianman National Natural Reserve; 27 Jun. 2006; Xiao-Cheng Shen leg.; GSFGPM • 1 क; Ankang, Pingheliang; alt. 2090 m; 11 Jul. 2010; Tao Li leg. Heilongjian Prov. • 1 q; Yichun, Fenglin; 20 Jul. 2008. - Jiangxi Prov. • 1 क; Yifeng, Guanshan National Natural Reserve; 9 May-1 Jun. 2009; interception trap.

\section{Diagnosis}

\section{Female}

Measurements. Body length $11.5 \mathrm{~mm}$. Fore wing length $10.5 \mathrm{~mm}$. Ovipositor sheath length $1.2 \mathrm{~mm}$.

HEAD. Face approximately $1.45 \times$ as wide as long, upper margin with a smooth small median tubercle. Upper tooth of mandible almost as long as lower tooth. Postocellar line approximately $0.75 \times$ as long as ocular-ocellar line. Antenna with 35 flagellomeres. Ratio of length from first to fifth flagellomeres: 2.8:1.9:1.9:1.8:1.7.

Mesosoma. Anterior, upper and lower portions of mesopleuron (Fig. 55) with fine, relatively sparse punctures. Metapleuron (Fig. 55) with sparse, even punctures. Fore wing with vein $1 \mathrm{cu}-\mathrm{a}$ distal to $1 / \mathrm{M}$ by $0.6 \times$ length of $1 \mathrm{cu}-\mathrm{a}$. Areolet large, obliquely quadrangular, receiving vein $2 \mathrm{~m}$-cu approximately $0.66 \times$ distance from vein 2 rs-m to 3 rs-m. Ratio of length of hind tarsomeres from first to fifth approximately: $6.3: 3.3: 2.8: 1.4: 1.9$. Claw densely pectinate. Propodeum with apical portion of lateral longitudinal carina present (Fig. 56).

Metasoma. Second tergite approximately $0.8 \times$ as long as apical width. Third tergite $0.95 \times$ as long as apical width. Fourth tergite $0.9 \times$ as long as apical width. Ovipositor sheath (Fig. 54) $3.0 \times$ as long as maximum width. Ovipositor with dorsal notch.

Coloration (Fig. 54). Black, except the following; flagellum reddish brown; face, clypeus, mandibles except teeth, maxillary and labial palpi, malar area, lateral spots of vertex, scutellum and subtegular ridges yellowish white; fore and middle legs (except coxae) yellowish brown; hind legs except dorsobasal portion and apexes of coxae, and all tergites almost entirely red-brown; tegulae yellow-brown.

\section{Ctenopelma rufescentis Sheng, 2009}

Figs $57-59$

Ctenopelma rufescentis Sheng in Sheng \& Sun, 2009: 121.

\section{Material examined}

CHINA - Henan Prov. 1 o , holotype; Neixiang, Baotianman National Natural Reserve; alt. 1280 m; 10 Jul. 2006; Xiao-Cheng Shen leg.; GSFGPM. - Jiangxi Prov.•1 9 ; Ji’an; alt. 174 m; 28 Jun. 2009; interception trap • 2 우; Yifeng, Guanshan National Natural Reserve; 7-9 May 2010; Shu-Ping Sun leg. 2 우; Yifeng, Guanshan National Natural Reserve; 20 Apr.-17 May 2016; interception trap • 1 O; Pingxiang, Mt. Wugongshan, Hongyangu; alt. 580 m; 26 Apr. 2016; Yu Yao leg. - Beijing • 1 o; Mentougou; 27 Jun. 2008; Tao Wang leg. 4 우; Mentougou; 16 Jun.-28 Jul. 2009; interception trap - 3 우; Mentougou; 15-22 Jul. 2011; interception trap • 1 क ; Mentougou; 30 Jul. 2014; interception trap. - Hubei Prov. • 3 q $\circ$; Shennongjia National Natural Reserve, Yiyuhe; 4 Jul.-1 Aug. 2011; interception trap.

\section{Diagnosis}

\section{Female}

Measurements. Body length $12.5 \mathrm{~mm}$. Fore wing length $11.5 \mathrm{~mm}$. Ovipositor sheath length $1.0 \mathrm{~mm}$. 


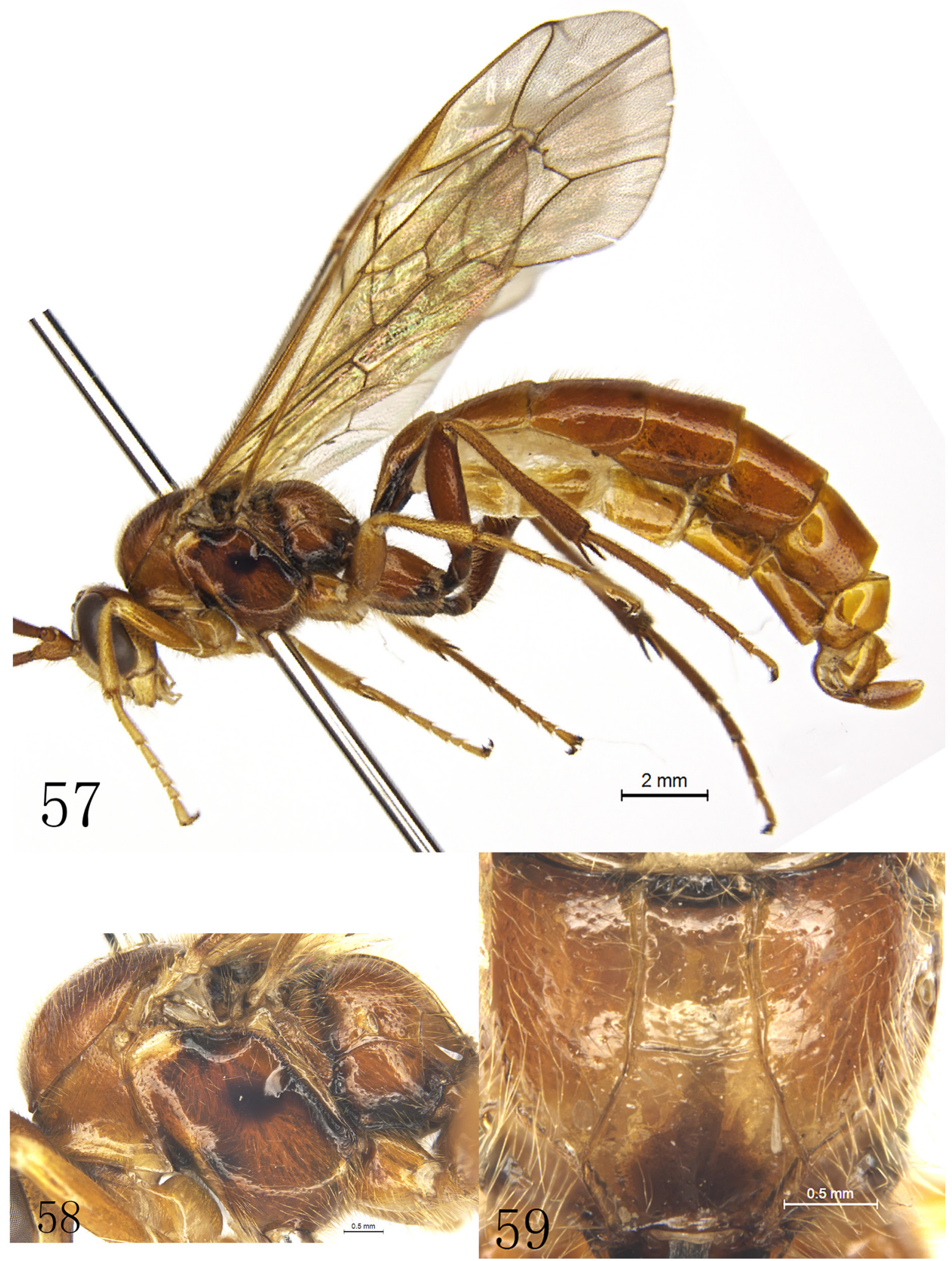

Figs 57-59. Ctenopelma rufescentis Sheng, 2009, holotype, $९$ (GSFGPM). 57. Habitus, lateral view. 58. Mesosoma, lateral view. 59. Propodeum. 
Head. Face approximately $1.5 \times$ as wide as long. Clypeus $2.8 \times$ as wide as long. Postocellar line approximately $0.6 \times$ as long as ocular-ocellar line. Ratio of length from first to fifth flagellomeres: 3.0:1.9:1.8:1.8:1.8.

Mesosoma. Mesopleuron (Fig. 58) smooth, shiny, anterior and lower margins with fine sparse punctures. Metapleuron (Fig. 58) with sparse indistinct punctures. Ratio of length of hind tarsomeres from first to fifth approximately: 7.4:3.5:2.9:1.5:2.1. Claw densely pectinate. Propodeum (Fig. 59) smooth, shiny, median longitudinal carinae between base and apical carina almost parallel, then evenly divergent posteriorly. Apical portion of lateral longitudinal carina present.

Metasoma. Second tergite approximately $0.9 \times$ as long as apical width. Third tergite $1.1 \times$ as long as apical width, posterior width slightly narrower than anterior width. Ovipositor sheath $2.9 \times$ as long as maximum width, apical half of dorsal profile slightly concave; apex circular in lateral view. Ovipositor with dorsal notch.

COLORATION (Fig. 57). Reddish brown, except following; face, clypeus except anterior margin, mandibles except teeth, maxillary and labial palpi, malar area, lower portion of gena, lateral portion of frons, scutellum and postscutellum, all whitish yellow; median portion of frons, posteromedian portion of mesopleuron and lower margion of metapleuron black; fore and middle legs brownish yellow; hind legs red-brown, except apexes of coxae and trochanters black; tegulae, subtegular ridges yellowish white.

\section{Ctenopelma tomentosum (Desvignes, 1856)}

Fig. 60

Campoplex tomentosus Desvignes, 1856: 100.

\section{Material examined}

CHINA - Liaoning Prov. • 2 q ; Kuandian, Baishilazi National Natural Reserve; alt. 400 m, 1-3 Jun. 2001; Mao-Ling Sheng leg. • 1 क; Kuandian; 16 Jul. 2007; Mao-Ling Sheng leg. 1 q; Kuandian; 16 Jun. 2017; Tao Li leg. • 1 क; Qianshan; 15 Jun. 2004; Mao-Ling Sheng leg. • 1 \&; Xinbin; 8 Jul. 2005; Mao-Ling Sheng leg. • 1 +; Xinbin; 23 Jul. 2006; interception trap • 2 q 9 ; Xinbin; 8 Jul.-26 Aug. 2009; interception trap - 1 क; Benxi; 15 Jul. 2015; reared from larva 'silk chamber' of Neurotoma sibirica Gussakovskij, 1935 by Mao-Ling Sheng • 5 + $q$; Benxi; 13 Jun. 2017; reared from larva 'silk chamber' of $N$. sibirica by Mao-Ling Sheng and Tao Li 11 + ; Benxi; 20 Jun. 2018; reared from larva's 'silk chamber' of $N$. sibirica by Tao Li • 1 O; Haicheng; 11 Jul. 2015; Tao Li leg. - Heilongjiang Prov. - 1 q; Chaihe; 21 Jun. 2004; Mao-Ling Sheng leg. - Jilin Prov. 1 q; Changbaishan National Natural Reserve; alt. 1870 m; 23 Jul. 2008; Mao-Ling Sheng leg.

\section{Host}

Neurotoma sibirica Gussakovskij, 1935.

\section{Host foodplant}

Sorbaria sorbifolia (L.) A.Braun.

\section{Differential diagnosis}

In light of the revision by Kasparyan (2004), three species from China, C. melanothoracicum Sheng, 2009, C. rufiscentis Sheng, 2009, and C. tomentosum Desvignes, 1856, belong to the C. tomentosum subgroup, and can be distinguished by the characters given in Table 1. 
Table 1. Comparision of Chinese species of genus Ctenopelma subgroup tomentosum.

\begin{tabular}{|c|c|c|c|}
\hline & C. melanothoracicum & C. rufiscentis & C. tomentosum \\
\hline $\begin{array}{l}\text { Lateral longitudinal } \\
\text { carinae of propodeum }\end{array}$ & $\begin{array}{l}\text { apical portion present } \\
\text { (Fig. 56) }\end{array}$ & $\begin{array}{l}\text { apical portion more or } \\
\text { less present (Fig. 59) }\end{array}$ & absent \\
\hline $\begin{array}{l}\text { Combined areae basalis } \\
\text { and superomedia }\end{array}$ & $\begin{array}{l}2.0 \times \text { as long as apical } \\
\text { width, slightly expanded } \\
\text { medially (Fig. 56) }\end{array}$ & $\begin{array}{l}1.4 \times \text { as long as apical } \\
\text { width, almost parallel } \\
\text { (Fig. 59) }\end{array}$ & $\begin{array}{l}2.0 \times \text { as long as apical } \\
\text { width, slightly narrowed } \\
\text { medially }\end{array}$ \\
\hline Mesopleuron & $\begin{array}{l}\text { with distinct punctures, } \\
\text { smooth centrally (Fig. 55) }\end{array}$ & $\begin{array}{l}\text { almost entirely } \\
\text { smooth, shiny (Fig. 58) }\end{array}$ & $\begin{array}{l}\text { with fine, sparse punctures, } \\
\text { smooth centrally }\end{array}$ \\
\hline Spiracle of propodeum & $1.7 \times$ as long as wide & $2.5 \times$ as long as wide & $1.8 \times$ as long as wide \\
\hline $\begin{array}{l}\text { Apex of ovipositor sheath } \\
\text { in lateral view }\end{array}$ & almost truncated & circular & more or less truncated \\
\hline Face & whitish yellow & yellow & black \\
\hline Mesosoma & black (Fig. 54) & reddish brown (Fig. 57) & black \\
\hline Tergites of metasoma & $\begin{array}{l}\text { almost entirely reddish } \\
\text { brown }\end{array}$ & $\begin{array}{l}\text { almost entirely reddish } \\
\text { brown }\end{array}$ & $\begin{array}{l}\text { black, or at least apical } \\
\text { portion black }\end{array}$ \\
\hline
\end{tabular}

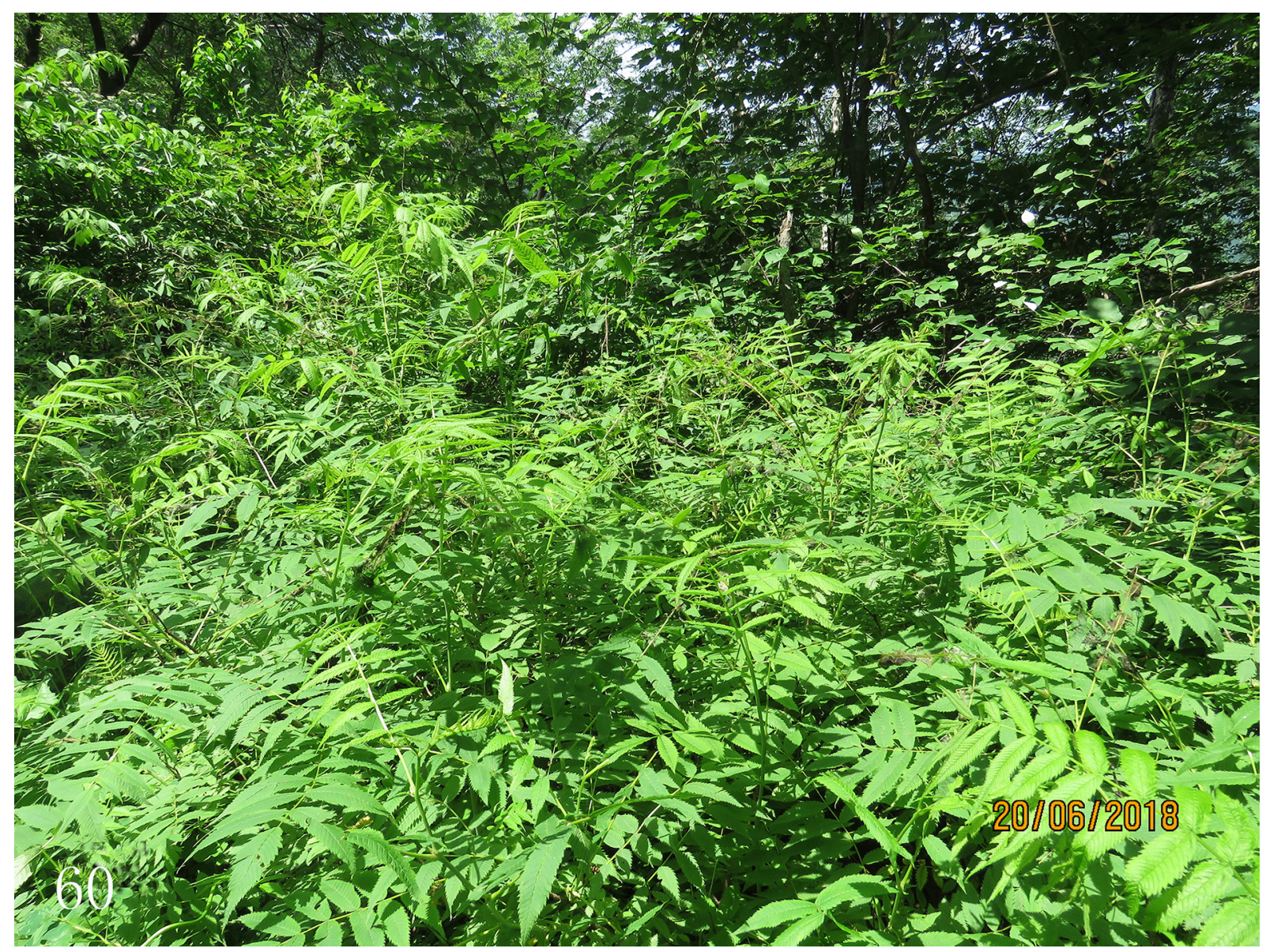

Fig. 60. Habitat of Ctenopelma tomentosum (Desvignes, 1856): the shrub, Sorbaria sorbifolia (L.) A.Braun, in Benxi, Laoning Province, China. 


\section{Discussion}

Ctenopelma tomentosum (Desvignes, 1856) is a transpalaearctic species (Kasparyan 2004). According to the specimens of $C$. tomentosum deposited in GSFGPM, NHMUK, ZISP and ZSMG, this species displays some distinct variation, including a wide range of coloration. This variation deserves further research, and specialists working in the abovementioned museums with access to specimens are encouraged to persue this line of study.

\section{Acknowledgements}

The authors are deeply grateful to Drs Gavin Broad (NHMUK) and Dmitri Kasparyan (ZISP) for their hard work and important comments. The authors also thank Drs Gavin Broad, Stefan Schmidt and Olga Schmidt (ZSMG) for their help while the first and corresponding authors were working in NHMUK and ZSMG; and Kyohei Watanabe (KPMNH) for taking some type photos of Ctenopelma Holmgren, 1857 from Japan. This research was supported by the National Natural Science Foundation of China (NSFC, No. 31110103062, No. 31501887) and by key project of Science-technology basic condition platform from The Ministry of Science and Technology of the People's Republic of China (Grant No. 2005DKA21402).

\section{References}

Aubert J.F. 1985. Ichneumonides Scolobatinae des collections suédoises (suite) et du Musée de Léningrad. Bulletin de la Société entomologique de Mulhouse 1985 (octobre-décembre): 49-58.

Aubert J.F. 1987. Deuxième prélude à une révision des Ichneumonides Scolobatinae. Bulletin de la Société Entomologique de Mulhouse 1987: 33-40.

Aubert J.F. 2000. The West Palaearctic ichneumonids and their hosts. 3. Scolobatinae (=Ctenopelmatinae) and supplements to preceding volumes. Les ichneumonides ouest-palearctiques et leurs hotes. 3 . Scolobatinae (=Ctenopelmatinae) et suppl. aux volumes precedents. Litterae Zoologicae 5: 1-310.

Barron J.R. 1981. The Nearctic species of Ctenopelma (Hymenoptera, Ichneumonidae, Ctenopelmatinae). Naturaliste Canadien 108 (1): 17-56.

Desvignes T. 1856. Catalogue of British Ichneumonidae in the collection of the British Museum. London.

Gauld I.D. 1991. The Ichneumonidae of Costa Rica, 1. Introduction, keys to subfamilies, and keys to the species of the lower Pimpliform subfamilies Rhyssinae, Poemeniinae, Acaenitinae and Cylloceriinae. Memoirs of the American Entomological Institute 47: 1-589.

Gravenhorst J.L.C. 1829. Ichneumonologia Europaea. Pars III. Vratislaviae.

Heinrich G.H. 1949. Ichneumoniden des Berchtesgadener Gebietes. (Hym.). Mitteilungen der Münchner Entomologischen Gesellschaft 35-39: 1-101.

Heinrich G.H. 1953. Ichneumoniden der Steiermark (Hym.). Bonner zoologische Beiträge 4: 147-185.

Holmgren A.E. 1857. Försök till uppställning och beskrifning af de i Sverige funna Tryphonider (Monographia Tryphonidum Sueciae). Kongliga Svenska Vetenskaps-Akademiens Handlingar. N.F.1 (1855): 93-246.

Kasparyan D.R. 2004. A review of Palaearctic species of the tribe Ctenopelmatini (Hymenoptera, Ichneumonidae). The genera Ctenopelma Holmgren and Homaspis Foerster. Entomologicheskoe Obozrenie 83 (2): 437-467. [In Russian.]

Li T., Sheng M.-L., Sun S.-P., Chen G.-F. \& Guo Z.-H. 2012. Effect of the trap color on the capture of ichneumonids wasps (Hymenoptera). Revista Colombiana de Entomología 38 (2): 338-342. 
Pschorn-Walcher H. 1990. A brief note on the biology and larvae of Megalodontes klugi Leach (Hymenoptera: Megalodontidae). Mitteilungen der Schweizerischen entomologischen Gesellschaft 63 (3-4): 303-308.

Rudow F. 1917. Ichneumoniden und ihre Wirte. Entomologische Zeitschrift 31: 66-67.

Shaw M.R., Kasparyan D.R. \& Fitton M.G. 2003. Revision of the British checklist of Ctenopelmatini (Hymenoptera: Ichneumonidae, Ctenopelmatinae). Entomologist's Gazette 54 (2): 137-141.

Sheng M.-L. \& Sun S.-P. 2009. Insect fauna of Henan, Hymenoptera: Ichneumonidae. Science Press, Beijing.

Sheng M.-L. \& Sun S.-P. 2014. Ichneumonid Fauna of Liaoning. Science Press, Beijing.

Townes H.K. 1970. The genera of Ichneumonidae, Part 3. Memoirs of the American Entomological Institute 13: 1-307.

Yu D.S., van Achterberg C. \& Horstmann K. 2016. Taxapad 2016, Ichneumonoidea 2015. Database on flash-drive. Nepean, Ontario.

Manuscript received: 17 April 2019

Manuscript accepted: 17 June 2019

Published on: 20 August 2019

Topic editor: Gavin Broad

Desk editor: Radka Rosenbaumová

Printed versions of all papers are also deposited in the libraries of the institutes that are members of the EJT consortium: Muséum national d'Histoire naturelle, Paris, France; Meise Botanic Garden, Belgium; Royal Museum for Central Africa, Tervuren, Belgium; Royal Belgian Institute of Natural Sciences, Brussels, Belgium; Natural History Museum of Denmark, Copenhagen, Denmark; Naturalis Biodiversity Center, Leiden, the Netherlands; Museo Nacional de Ciencias Naturales-CSIC, Madrid, Spain; Real Jardín Botánico de Madrid CSIC, Spain; Zoological Research Museum Alexander Koenig, Bonn, Germany; National Museum, Prague, Czech Republic. 